Article

\title{
Climate Scenarios and Agricultural Indices: A Case Study for Switzerland
}

\author{
Flavian Tschurr ${ }^{1}$ (D), Iris Feigenwinter ${ }^{2}$, Andreas M. Fischer ${ }^{1}$ and Sven Kotlarski ${ }^{1, *(D)}$ \\ 1 Federal Office of Meteorology and Climatology MeteoSwiss, CH-8058 Zurich, Switzerland; \\ ftschurr@ethz.ch (F.T.); andreas.fischer@meteoswiss.ch (A.M.F.) \\ 2 Department of Environmental Systems Science, ETH Zurich, CH-8092 Zurich, Switzerland; \\ iris.feigenwinter@usys.ethz.ch \\ * Correspondence: sven.kotlarski@meteoswiss.ch
}

Received: 16 April 2020; Accepted: 20 May 2020; Published: 21 May 2020

\begin{abstract}
The $\mathrm{CH} 2018$ Climate Scenarios for Switzerland are evaluated with respect to the representation of 24 indices with agricultural relevance. Furthermore, future projections of the considered indices until the end of the 21st century are analyzed for two greenhouse gas scenarios (Representative Concentrations Pathways RCP2.6 and RCP8.5). The validation reveals good results for indices that are based on one or two climate variables only and on simple temporal aggregations. Indices that involve multiple climate variables, complex temporal statistics or extreme conditions are less well represented. The climate projection analysis indicates an intensification of temperature-related extreme events such as heat waves. In general, climate change signals in the indices considered are subject to three main patterns: a horizontal pattern across Switzerland, a vertical pattern depending on elevation and a temporal pattern with an intensification of change in the course of the 21st century. Changes are in most cases more pronounced for the high-emission RCP8.5 scenario compared to the mitigation scenario RCP2.6. Overall, the projections indicate a challenging 21st century climate for the agricultural sector. Our findings furthermore show the value and the necessity of a robust validation of climate scenario products to enable trustworthy and valuable impact analyses, especially for more complex indices and models.
\end{abstract}

Keywords: downscaling; climate indicators; agriculture; CH2018; climate scenarios; climate indices; climate extremes

\section{Introduction}

Since pre-industrial times, the global mean temperature has risen by almost $1^{\circ} \mathrm{C}$ [1]. Human influence is clear and has been detected in a range of warming indicators [2]. According to the Intergovernmental Panel on Climate Change (IPCC), it is extremely likely that human influence has been the dominant cause of global warming since the mid-20th century [3]. Future climate projections consistently indicate a further global scale warming in the course of the 21st century. Warming rates depend on the specific greenhouse gas emission scenario assumed and are accompanied by changes in further climate variables [4]. The impacts of these past climatic changes are manifold and traceable worldwide, but with region-specific characteristics and patterns. It is at the regional scale, where the impacts of climate change affect a wide range of natural and anthropogenic systems and sectors [5]. Among others, agricultural practice can be heavily impacted and might ultimately have to adapt to changes in the prevailing climate (e.g., [6-8]). Adaptation options, in general, are manifold and can include diversified crop rotations, changes to cultivation and water management or participation in dedicated insurance schemes $[9,10]$. In some regions though, adaptation cannot be an option any longer and agriculture would have to be given up with a further increase of global warming [11]. 
In order to assess the agricultural impacts of future climate change, reliable and robust information on the nature of these changes is required. On regional scales and especially in areas subject to a pronounced spatial climate variability, the spatial resolution of global climate model output is typically insufficient and a further refinement by dynamical or statistical downscaling techniques is needed (e.g., [12,13]). The WCRP CORDEX (Coordinated Regional Climate Downscaling Experiment; [14]) initiative has recently produced a large number of regional climate change projections for all terrestrial regions of the globe employing a large set of regional climate models (RCMs) nested into the Coupled Model Intercomparison Project 5 (CMIP5) global climate model (GCM) output [15]. For the European continent, the European branch of CORDEX (EURO-CORDEX) currently provides more than 100 regional climate change simulations until the year 2100 at a spatial resolution of about 12 and $50 \mathrm{~km}[16,17]$.

In several European countries, the EURO-CORDEX simulation ensemble provides the basis for national reference climate scenarios in support of national climate adaptation plans. One of these countries is Switzerland, where the CH2018 Climate Scenarios for Switzerland were released in November 2018 (see Chapter 2). In most cases, the establishment of national climate scenarios involves a post processing of raw climate model output to correct for remaining simulation biases, to further downscale the results to local scales and to provide an uncertainty assessment. The resulting scenario products are typically geared towards a broad applicability, i.e., they try to serve a wide range of user communities and user needs across various sectors. As a consequence, these scenarios are not necessarily optimized for all sector-specific applications and, furthermore, are subject to a number of limitations that have to be carefully assessed and considered before subsequent usage (e.g., [18-20]).

For the case of Switzerland, we here evaluate the applicability of the CH2018 scenarios for quantitative climate impact applications in agriculture at local scale. A number of common climate indices have previously been calculated based on the local-scale CH2018 data. However, an in-depth analysis of agriculture-relevant indices has been missing so far. We focus on indices that inform on primary production but also on livestock farming. Where applicable, we assess and discuss projected future changes of these indices, including the inherent modelling and emission scenario uncertainties. The underlying research questions are:

1. To what extent are agricultural climate indices at the local scale represented by the $\mathrm{CH} 2018$ Climate Scenarios for Switzerland? Can remaining biases in the representation of those indices be quantified?

2. How will future climate change impact agricultural climate indices in Switzerland?

Providing answers to these two questions will, first of all, inform agricultural impact modelers in Switzerland about the direct usability of the $\mathrm{CH} 2018$ scenarios for index-based climate impact assessments in the agricultural sector by uncovering potential limitations of the local scale CH2018 scenario products. Second, the spatially explicit analysis of climate change signals in agricultural indices at local scale will provide an extended picture of potential impacts of future climate change in Switzerland.

The interpretation of the results is not limited to Switzerland but is, in a broader sense, also highly relevant for further neighboring regions/nations that are likely to experience similar future changes in their climate. It is also relevant for those countries that employ local climate scenario data of the same type as in CH2018 such as Austria and their national ÖKS15 climate scenarios [21].

\section{The CH2018 Climate Scenarios}

In Switzerland, national climate change scenarios are being published on a regular basis through an official mandate by the Swiss government through its Action Plan on Climate Change Adaptation. The Federal Office of Meteorology and Climatology MeteoSwiss coordinates and conducts these activities in close collaboration with research institutions under the umbrella of the Swiss National Centre for Climate Services (NCCS). The national scenarios inform stakeholders from the public and 
private sector on how climate change affects Switzerland and represent the key basis for planning purposes in the field of climate adaptation.

The third generation of national climate change scenarios-the CH2018 Climate Scenarios for Switzerland-was released in November 2018 [22]. The new scenarios are the result of a joint collaboration among MeteoSwiss and ETH Zurich as main partners. Like earlier climate scenario assessments for Switzerland, the CH2018 scenarios build upon the latest RCM projections for Europe produced in internationally coordinated projects of leading European climate institutes. Specifically, the climate simulations underlying $\mathrm{CH} 2018$ are provided by the European branch of the Coordinated Regional Climate Downscaling Experiment (EURO-CORDEX) taking into account the three emission scenarios RCP2.6, RCP4.5 and RCP8.5 [23]. In total, 68 transient simulations carried out by different combinations of global and regional climate models are considered in $\mathrm{CH} 2018(12,25$ and 31 simulations for greenhouse gas scenarios RCP2.6, RCP4.5 and RCP8.5, respectively; note that the present work only covers RCP2.6 and RCP8.5). In addition to an overall rise in air temperature, they reveal four main changes that will shape the climate in Switzerland by mid-century in the absence of strong mitigation efforts (i.e., scenario RCP8.5):

1. Dry summers: Near-surface air temperature will rise in the summer months by $2.5^{\circ} \mathrm{C}$ to $4.5^{\circ} \mathrm{C}$ in comparison to today. At the same time, there is up to a quarter less rainfall, and the longest dry period without precipitation will last nearly 3 weeks.

2. More hot days: On the hottest days, it will be $2{ }^{\circ} \mathrm{C}$ to $5.5^{\circ} \mathrm{C}$ warmer than now. Hot summers such as those of the record years 2003 and 2018 could thus become the norm. Heatwaves will become more frequent and more intense.

3. Heavy precipitation: Individual heavy precipitation events will be more frequent and more intense in the future than today. The intensity of a 100-year precipitation event will increase by about $20 \%$. The projected changes in the intensity of heavy precipitation events on daily to hourly time scales are consistent with an increase of $6-7 \%$ per degree warming.

4. Snow-scarce winters: Winters will be considerably warmer than current ones. The zero-degree line could rise from today $850 \mathrm{~m}$ to about $1500 \mathrm{~m}$ above sea level. Snow will therefore become less frequent.

With strong climate mitigation efforts (i.e., scenario RCP2.6), about half of these potential changes in Switzerland's climate could be avoided by mid-century (compared to RCP8.5). The results from the climate scenarios $\mathrm{CH} 2018$ were published and disseminated through various channels following the results of a comprehensive user survey across various sectors. The product portfolio of $\mathrm{CH} 2018$ comprises a written technical report with results and methods in full detail, a brochure [24] and a website [25] with the results explained in simplified language, a web-atlas with several thousand standardized graphics and, finally, localized scenario data that are freely available targeting researchers of climate impacts.

The climate change scenarios $\mathrm{CH} 2018$ are considered as a main starting point for triggering the climate services value chain; they thus form the basis for planning measures in the field of climate adaptation and mitigation. For instance, the $\mathrm{CH} 2018$ scenarios serve as the reference projections for the Swiss pilot program on climate-change adaptation, as well as for downstream priority themes of the NCCS, such as hydrological scenarios or spread of agricultural pests. Finally, the results of CH2018 will feed into the third part of the Swiss' adaptation strategy on climate change adaptation.

\section{Data and Methods}

\subsection{Data}

The $\mathrm{CH} 2018$ scenarios provide a range of user products that represent different levels of information detail and of data complexity (see [26] for an overview). The most advanced data products are the localized transient daily scenarios at site scale and on a regular $2 \mathrm{~km}$ grid covering entire Switzerland: 
DAILY-LOCAL and DAILY-GRIDDED. These datasets are intended for use in quantitative climate impact assessments at regional and local scales. They provide transient time series at daily resolution for the period 1981-2099 for seven (DAILY-LOCAL) and four (DAILY-GRIDDED) climate variables, respectively, and for all 68 individual climate model simulations considered. They have been constructed by bias-correcting and downscaling the raw EURO-CORDEX climate model output available at resolutions of about $12 \mathrm{~km}$ and $50 \mathrm{~km}$. Within CH2018, the DAILY-LOCAL and DAILY-GRIDDED products were used to calculate different climate indices such as temperature indices (e.g., hot days, tropical nights or frost days), heat stress (wet bulb temperature) or drought indices (see Chapter 6, CH2018 2018). So far, there has been no explicit focus on agricultural aspects. These will be covered in the present work which, however, only considers the DAILY-LOCAL product (scenarios at stations) as it provides more climate variables than the DAILY-GRIDDED dataset: mean, minimum and maximum near-surface air temperature; precipitation; relative humidity; global radiation; near surface wind speed. For reasons of simplicity, we only consider emission scenarios RCP2.6 (strong mitigation efforts) and RCP8.5 (unabated greenhouse gas emissions). Furthermore, we do not employ the full set of 68 transient simulations available in $\mathrm{CH} 2018$ but the so-called multi-model combination, a sub-ensemble that reduces inter-dependencies among the set of RCM simulations and that ensures a consistent comparison between greenhouse gas scenarios. The multi-model combination has been constructed by a time-shift approach and provides the same set of 21 climate model chains (combination of a specific GCM with a specific RCM) for each of the three RCPs and for each future scenario period (see below). The drawback of this method is that the transient nature of the climate scenario data is lost. For further details, the reader is referred to CH2018 [22] and Soerland et al. [27]. A list of all GCM-RCM model chains covered by the CH2018 multi-model combination is available in CH2018 [22] (Table 4.1 therein).

The statistical bias correction and downscaling method employed for constructing DAILY-LOCAL is quantile mapping (QM); e.g., [28-30]. QM is a distribution-based technique that calibrates a transfer function between raw climate model output and observational series in a historical calibration period (1981-2010 in CH2018). It ensures an approximate match of distributional quantiles in the bias-corrected climate model output and in the observed reference series, respectively. In a second step, the calibrated transfer function is used to bias-correct the raw climate model output also beyond the calibration period and in the future scenario period (2011-2099 in the present case). See Feigenwinter et al. [18] and Kotlarski et al. [31] for further methodological details.

While QM, by definition, ensures the reproduction of observational distributional quantiles in the historical calibration period, further characteristics of the observed reference climate are not necessarily represented by the "bias-corrected" climate model output. The temporal sequence of daily values, for instance, is inherited from the raw climate model. In case the latter is biased in terms of temporal variability at daily scale (e.g., a too high or too low temporal autocorrelation or persistence), the derived bias-corrected product is likely to suffer from these biases as well. Among others, this has potentially large implications for agricultural indices where for instance spell lengths are of importance. A further potential shortcoming concerns indices that combine several meteorological variables. The QM variant employed in $\mathrm{CH} 2018$ is of univariate nature, i.e., the bias correction is carried out separately for each of the seven individual variables and inter-variable consistency is not explicitly considered. If the consistency at daily scale between variables is misrepresented in the raw climate model, there is a good chance that it is also misrepresented in the bias-corrected data. One example are heat waves in the absence of rainfall over a long duration.

Remaining inaccuracies in the bias-corrected data, such as the ones described above, imply the requirement for a careful evaluation of the $\mathrm{CH} 2018$ data before using them in climate impact applications and before interpreting sector-specific climate indicators. A basic requirement in index-based climate analysis is a fair representation of the specific climate index by the bias-corrected data in the historical calibration period. The present work carries out such an evaluation for a large range of climate indices with agricultural relevance. The number of available stations that are covered by DAILY-LOCAL 
depends on the specific variable considered and ranges from 59 for global radiation to 399 for precipitation; see Feigenwinter et al. [18] and Kotlarski et al. [31] for further details. We here employ a subset of 68 stations only for which most variables are available (see Figure 1).

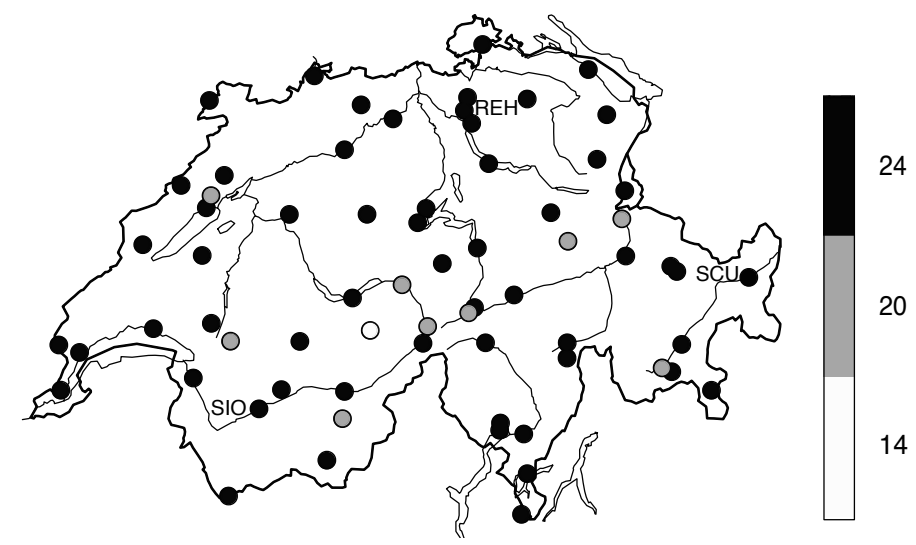

Figure 1. Location of the 68 stations covered by this work and number of calculated indices at each station. Per station a set of at least 14 indices is available, the maximum number is 24 . Three stations, representing the agricultural climate of Switzerland are tagged: Sion (SIO) in the dry Rhone valley in Valais, Zurich/Reckenholz (REH) in the Alpine forelands and Scuol (SCU) in the Alpine region of the Engadine.

For validating the representation of climate indices in the CH2018 DAILY-LOCAL product in the period 1981-2010, we use observational time series at daily resolution measured at the 68 considered stations as reference. These observational series are identical to the ones employed during the calibration of the QM transfer function (see above).

Both the observed series and the QM bias-corrected series may contain individual days or shorter periods of missing data. Reasons are observational measurement gaps in the first case, and the use of non-standard calendars by individual GCM-RCM simulations in the second case. Data gaps were replaced by values for the corresponding day-of-the-year in the previous year. If this value was not available (e.g., gap in the first year of the period), the missing value was replaced by the value for the corresponding day-of-the-year of the next available year.

\subsection{Indices}

The dependency of agricultural practice on the environmental conditions and, hence, the prevailing climate is often complex. Many different circumstances need to occur together, so that optimal production, i.e., yield can be ensured. For instance, optimal radiative conditions are not sufficient to ensure production, but also temperature and humidity conditions have to be favorable. In the present work, these complex inter-dependencies are represented by a number of agricultural climate indices that are relevant for agricultural practice and that are covered by the relevant literature.

In total 24 different indices are evaluated here (see Table 1 for the definitions), taking different sectors of agriculture into consideration, meaning livestock as well as plant-specific indices. They can be clustered into indices informing on droughts, heat/cold waves, degree days, and further agriculture-specific indices (others). Regarding the livestock sector, animal health-specific indices such as the heatwave and degree day indices are especially relevant. For the plant sector, drought and further agriculture-specific indices are of relevance. Within each category a number of different indices are analyzed that take into account either different climate variables or different temporal structures. Each index was computed for all available stations and model chains in both the observations and in the $\mathrm{CH} 2018$ QM data. 
Table 1. Description and definition of the indices used in this study with the corresponding unit, subtopic and the required climate variables (daily mean temperature (tas), daily minimum temperature (tasmin), daily maximum temperature (tasmax), precipitation (pr) and global radiation (rsds)).

\begin{tabular}{|c|c|c|c|c|}
\hline Index & Description & Unit & Climate Variables & Subtopic \\
\hline CDD & $\begin{array}{l}\text { Consecutive Dry Days are defined as the } \\
\text { longest yearly period with a daily } \\
\text { precipitation below } 1 \mathrm{~mm} \text { [32]. For each } \\
\text { period the average of all yearly maximum } \\
\text { values within the considered 30-year } \\
\text { period was calculated. }\end{array}$ & Days & pr & drought \\
\hline CDDVeg & $\begin{array}{l}\text { CDDs within the vegetation period. The } \\
\text { vegetation period is defined as the period } \\
\text { between the first occurrence of a } \\
\text { 6-day-period with daily mean } \\
\text { temperatures above } 5^{\circ} \mathrm{C} \text { and the first } \\
\text { occurrence of a } 6 \text {-day-period with daily } \\
\text { mean temperatures below } 5{ }^{\circ} \mathrm{C} \text { after the } \\
\text { first of July [33]. }\end{array}$ & Days & pr, tas & drought \\
\hline CoolingDD & $\begin{array}{l}\text { Cooling Degree Days are the yearly sum } \\
\text { of the differences between the daily mean } \\
\text { air temperature and a threshold } \\
\text { temperature }\left(18.3^{\circ} \mathrm{C} ;[34]\right) \text { above which } \\
\text { cooling of buildings is assumed to be } \\
\text { needed }[33,35] \text {. For each period the } \\
\text { average of all yearly sums within the } \\
\text { considered } 30 \text {-year period was calculated. }\end{array}$ & ${ }^{\circ} \mathrm{C}$ & tas & degree day \\
\hline CWC & $\begin{array}{l}\text { Cold Wave Counter: this index counts the } \\
\text { yearly number of events with five or } \\
\text { more consecutive days with daily } \\
\text { minimum temperatures below } 0{ }^{\circ} \mathrm{C} \text {. For } \\
\text { each } 30 \text {-year period the average of the } \\
\text { yearly number of events was calculated. }\end{array}$ & \# Events & tasmin & waves \\
\hline DTR & $\begin{array}{l}\text { The Diurnal Temperature Range is the } \\
\text { mean daily range between minimum and } \\
\text { maximum temperature. An increased } \\
\text { DTR has been observed to be associated } \\
\text { with crop yield losses [36]. }\end{array}$ & ${ }^{\circ} \mathrm{C}$ & tasmin, tasmax & others \\
\hline GDD & $\begin{array}{l}\text { Growing Degree Days are defined as the } \\
\text { yearly sum of the daily mean temperature } \\
\text { in }{ }^{\circ} \mathrm{C} \text { above a base temperature (here } 5 \\
\left.{ }^{\circ} \mathrm{C}\right) \text {. GDDs are widely used in plant } \\
\text { phenology modelling as they correlate } \\
\text { well with plant growth and plant } \\
\text { development, respectively }[37,38] \text {. For } \\
\text { each } 30 \text {-year period the average of all } \\
\text { yearly sums within the considered period } \\
\text { was calculated. }\end{array}$ & ${ }^{\circ} \mathrm{C}$ & tas & degree day \\
\hline
\end{tabular}


Table 1. Cont.

\begin{tabular}{|c|c|c|c|c|}
\hline Index & Description & Unit & Climate Variables & Subtopic \\
\hline GSL & $\begin{array}{l}\text { The Growing Season Length is defined as } \\
\text { the yearly number of days which are } \\
\text { between the first occurrence of a } \\
\text { 6-day-period with daily mean } \\
\text { temperatures above } 5^{\circ} \mathrm{C} \text { and the first } \\
\text { occurrence of a } 6 \text {-day-period with daily } \\
\text { mean temperatures below } 5^{\circ} \mathrm{C} \text { after } 1 \\
\text { July [33]. This season indicates the } \\
\text { timespan in which a broad spectrum of } \\
\text { plant species is growing. For each } 30 \text {-year } \\
\text { period the average length of all yearly } \\
\text { growing season lengths within the } \\
\text { considered period was calculated. }\end{array}$ & Days & tas & others \\
\hline & $\begin{array}{l}\text { Heating Degree Days are the yearly } \\
\text { temperature sum of the difference } \\
\text { between the daily mean air temperature } \\
\text { at days with mean temperatures below } 12 \\
{ }^{\circ} \mathrm{C} \text { and a threshold temperature } \\
\text { representing the inside of a building. }\end{array}$ & & & \\
\hline HDD & $\begin{array}{l}\text { HDD was calculated following the } \\
\text { definition of Christenson et al. [35] with a } \\
\text { room threshold temperature of } 20^{\circ} \mathrm{C} \\
\text { coming from the Swiss SIA norm } 381 / 3 \\
\text { [39]. For each 30-year period the average } \\
\text { of all yearly sums within the considered } \\
\text { period was calculated. }\end{array}$ & ${ }^{\circ} \mathrm{C}$ & tas & degree day \\
\hline HPE & $\begin{array}{l}\text { Heavy Precipitation Events are defined as } \\
\text { the yearly number of days with a } \\
\text { precipitation amount of } 50 \mathrm{~mm} \text { or more. } \\
\text { For each } 30 \text {-year period the average of all } \\
\text { yearly events within the considered } \\
\text { period was calculated. }\end{array}$ & \# Events & pr & others \\
\hline HWC & $\begin{array}{l}\text { Heat Wave Counter: This index counts } \\
\text { the yearly number of events with five or } \\
\text { more consecutive days with maximal } \\
\text { temperatures above } 30^{\circ} \mathrm{C} \text {. Threshold was } \\
\text { chosen accordingly to the } \mathrm{CH} 2018 \\
\text { Technical Report. For each } 30 \text {-year period } \\
\text { the average of all yearly events within the } \\
\text { considered period was calculated. }\end{array}$ & \# Events & tasmax & $\begin{array}{l}\text { heat and } \\
\text { cold waves }\end{array}$ \\
\hline HWL & $\begin{array}{l}\text { Heat Wave Length is defined as the } \\
\text { longest consecutive period with daily } \\
\text { maximum temperatures above } 30^{\circ} \mathrm{C} \\
\text { within a } 30 \text { years period. }\end{array}$ & Days & tasmax & $\begin{array}{l}\text { heat and } \\
\text { cold waves }\end{array}$ \\
\hline MHWL & $\begin{array}{l}\text { Mean Heat Wave Length is defined as the } \\
\text { average length of the yearly longest } \\
\text { consecutive period with daily maximum } \\
\text { temperatures above } 30^{\circ} \mathrm{C} \text { within a } 30 \\
\text { years period. }\end{array}$ & Days & tasmax & $\begin{array}{l}\text { heat and } \\
\text { cold waves }\end{array}$ \\
\hline
\end{tabular}


Table 1. Cont.

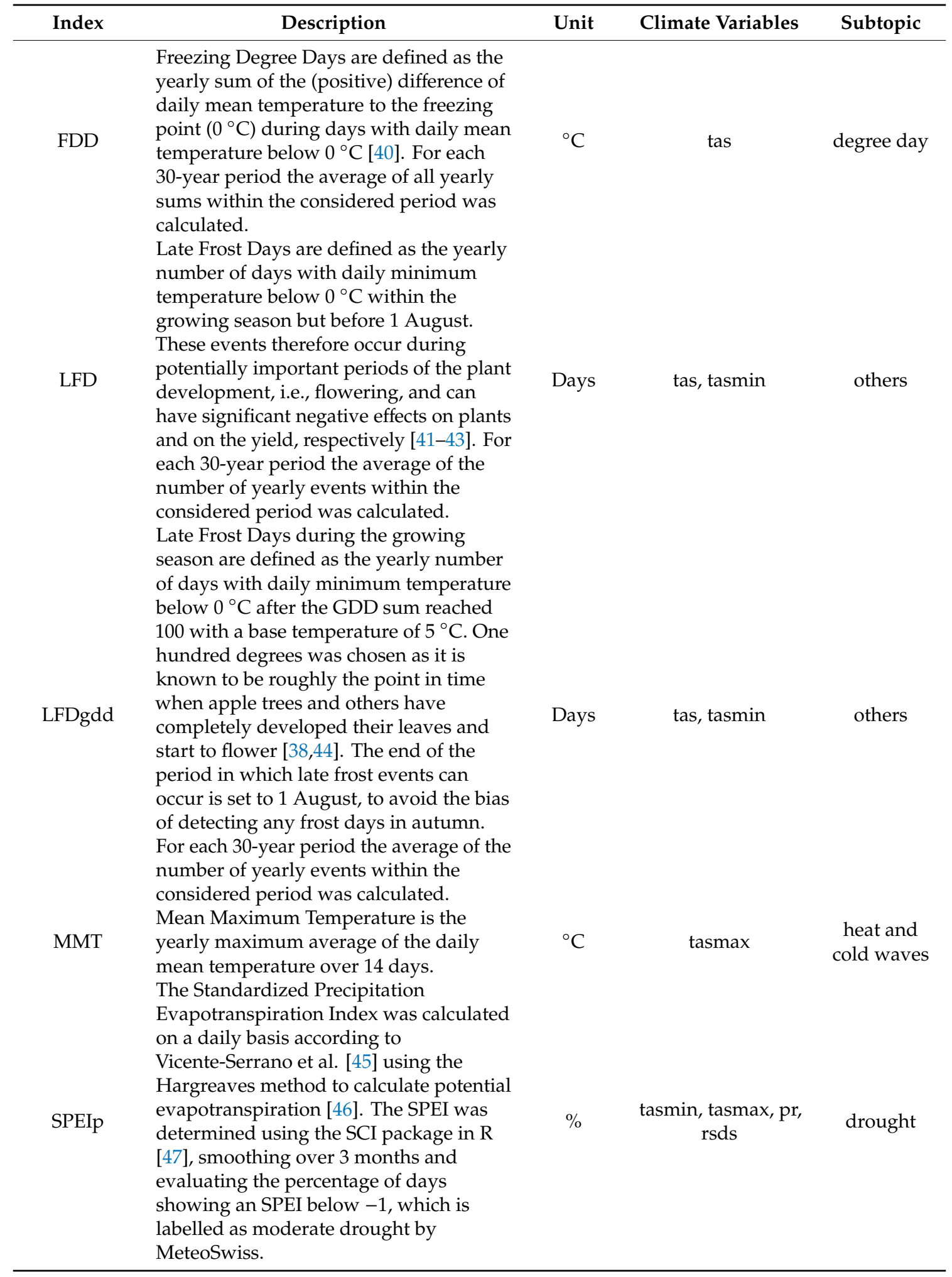


Table 1. Cont.

\begin{tabular}{|c|c|c|c|c|}
\hline Index & Description & Unit & Climate Variables & Subtopic \\
\hline SPEIe & $\begin{array}{l}\text { SPEIe is determined in the same manner } \\
\text { as the SPEIp but counts the yearly } \\
\text { number of events for which SPEI values } \\
\text { were below }-1.6 \text { (extreme drought event) } \\
\text { over at least } 7 \text { consecutive days within } \\
\text { the vegetation period (calculated } \\
\text { according to the GSL index). For each } \\
30 \text {-year period, the average of all yearly } \\
\text { numbers of events within the considered } \\
\text { period was calculated. }\end{array}$ & \# Events & $\begin{array}{c}\text { tas, tasmin, tasmax, } \\
\text { pr, rsds }\end{array}$ & drought \\
\hline SPEIl & $\begin{array}{l}\text { The Index SPEIl represents the average of } \\
\text { the yearly longest events that show } \\
\text { consecutive days with SPEI values below } \\
-1.6 \text { during the vegetation period. }\end{array}$ & Days & $\begin{array}{c}\text { tas, tasmin, tasmax, } \\
\text { pr, rsds }\end{array}$ & drought \\
\hline SPEIpVeg & $\begin{array}{l}\text { SPEIpVeg is calculated identically to the } \\
\text { SPEIp but describes the number of days } \\
\text { below }-1 \text { within the vegetation period } \\
\text { (determined as described for the GSL } \\
\text { index), as a proxy for plant growth } \\
\text { relevant droughts. }\end{array}$ & $\%$ & $\begin{array}{l}\text { tas, tasmin, tasmax, } \\
\text { pr, rsds }\end{array}$ & drought \\
\hline SPIp & $\begin{array}{l}\text { The Standardized Precipitation Index is } \\
\text { the simplified version of the SPEI. It does } \\
\text { not take evapotranspiration into } \\
\text { consideration and is calculated according } \\
\text { to McKee et al. [48]. The SCI package in R } \\
\text { [47] was used, smoothing over } 3 \text { months } \\
\text { and evaluating the percentage of days } \\
\text { showing an SPI below -1, which is } \\
\text { labelled as moderate drought by }\end{array}$ & $\%$ & pr & drought \\
\hline SPIe & $\begin{array}{l}\text { MeteoSwiss. } \\
\text { Uses the same calculation for the SPI as } \\
\text { described above but counts the yearly } \\
\text { number of events which show SPI values } \\
\text { below - } 1.6 \text { (extreme drought event) over } \\
\text { at least } 7 \text { consecutives days within the } \\
\text { vegetation period (calculated according } \\
\text { to the GSL index). For each } 30 \text {-year } \\
\text { period the average of all yearly numbers } \\
\text { of events within the considered period } \\
\text { was calculated. }\end{array}$ & \# Events & tas, pr & drought \\
\hline SPIpVeg & $\begin{array}{l}\text { SPIpVeg is calculated identically to the } \\
\text { SPIp but takes into account the days } \\
\text { below }-1 \text { within the vegetation period } \\
\text { (determined as described for the GSL } \\
\text { index), as a proxy for plant growth } \\
\text { relevant droughts. }\end{array}$ & $\%$ & tas, pr & drought \\
\hline TDD & $\begin{array}{l}\text { Thawing Degree Days are defined as the } \\
\text { yearly sum of the (positive) difference of } \\
\text { daily mean temperature to the freezing } \\
\text { point }\left(0^{\circ} \mathrm{C}\right) \text { during days with daily mean } \\
\text { temperature above } 0{ }^{\circ} \mathrm{C}[40] \text {. For each } \\
\text { 30-year period the average of all yearly } \\
\text { sums within the considered period was } \\
\text { calculated. }\end{array}$ & ${ }^{\circ} \mathrm{C}$ & tas & degree day \\
\hline
\end{tabular}




\subsection{Methods}

As outlined above, the present work covers both an evaluation of $\mathrm{CH} 2018$ with respect to agricultural indices and the analysis of projected climate change signals. First, each index was subject to a validation of the quantile-mapped data in the historical 30-year period 1981-2010 against observed data. As a primary skill score, the root-mean-square error (RMSE) between the simulated mean value and the observations has been calculated to express the quality of the downscaled model simulations. In order to avoid a too large weight on certain RCMs which are represented more often in the data, the mean simulated index value of all model chains $(q m(I))$ employing a specific RCM was calculated first ( $\mathrm{n}$ indicating the number of individual RCMs). Note that this averaging over RCMs was done in the validation routine only. It is motivated by the assumption of a strong contribution of the RCM formulation to remaining biases particularly in the inter-variable relationship after application of QM. The values averaged over RCMs were then used to calculate the mean simulated value across all model simulations (Equation (1)).

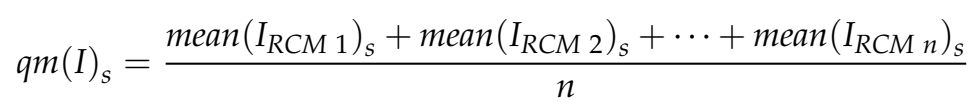

As a direct RMSE comparison among indices implies inconsistencies due to different units and different ensemble ranges, the RMSE needed to be standardized. This was achieved by dividing the obtained RMSE by the standard deviation (SD) of the observational index values (obs(I)) across stations (Equation (2)).

$$
\frac{R M S E(I)}{S D(I)}=\frac{\sqrt{\text { mean }\left(\left(q m(I)_{s}-o b s(I)_{s}\right)^{2}\right)}}{S D(I)}
$$

where $\mathrm{n}=$ number of individual RCMs; $\mathrm{s}=$ station index; $\mathrm{I}=$ given index.

If the standardized RMSE was below 0.5, the index was rated as well-performing (class A), otherwise as biased (class B). Note that the employed threshold of 0.5 has a strong subjective component, but based on the visual inspection of the evaluation figures approximately separates well-performing from poor-performing indices.

In a second step, climate change signals of both class A and class B indices were computed for three future time periods 2035 (2020-2049), 2060 (2045-2074) and 2085 (2070-2099) with respect to the historical reference period 1981-2010, similarly as in the official set of national scenarios (CH2018, 2018). While a certain confidence into the resulting signals for class A indices can be assumed (good evaluation results), those for class B indices should be interpreted with care only (poor evaluation results).

\section{Validation}

The summarized validation of the 24 indices for all individual stations considered is shown in Figure 2. The performance of the QM process for the individual indices is represented by the standardized RMSE. Additionally, vertical grey bars represent the climate model uncertainty at the respective station, i.e., the range of the respective index value across all quantile-mapped climate model chains of our chosen illustrative set of stations. The red trend line summarizes the linear regression between the medians of the quantile-mapped data (black dots) and the respective observations. If this red line and/or the black dots are following the 1:1 line (dashed grey line), the respective index is perfectly represented by the ensemble medians. 

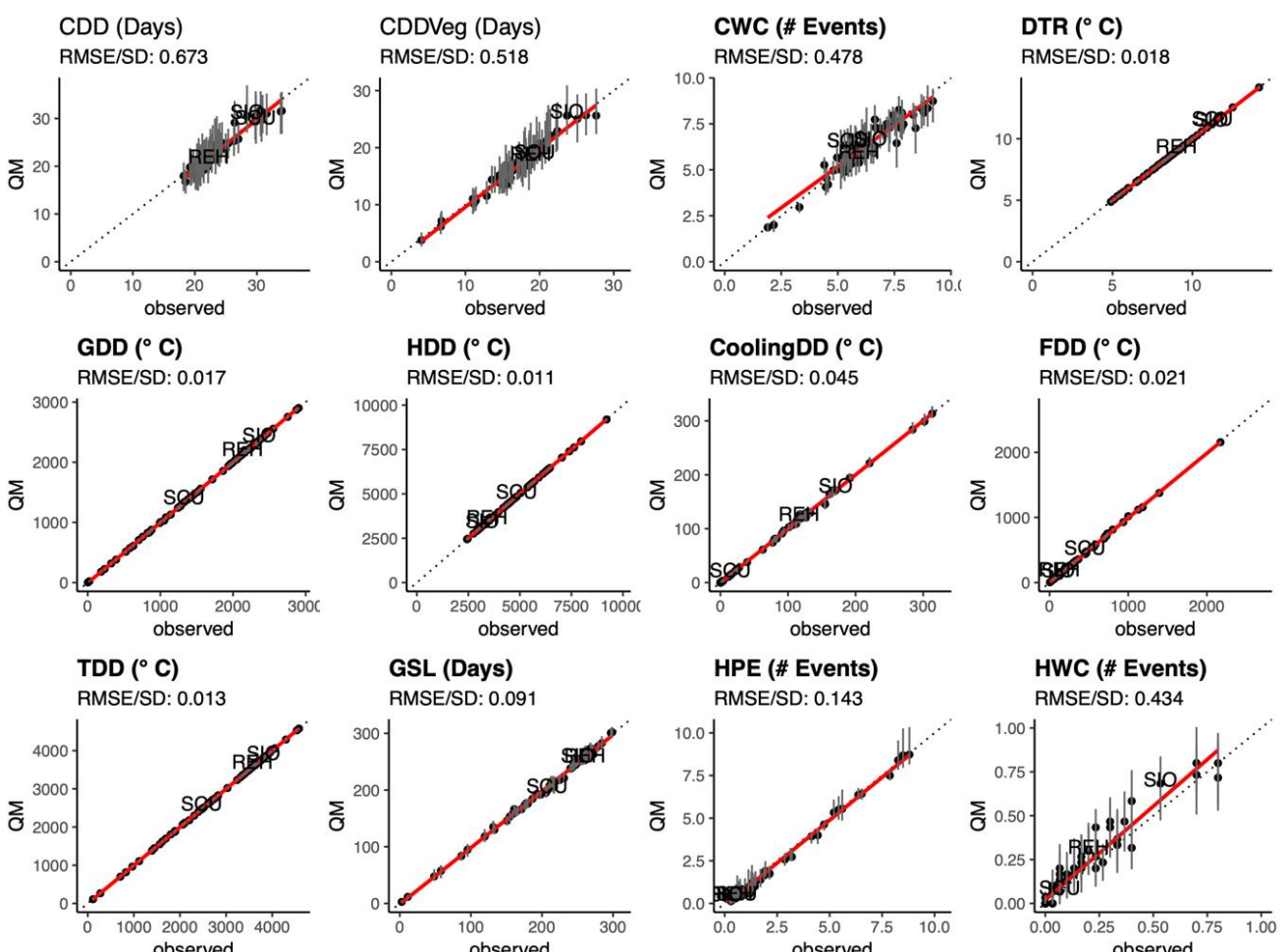

\section{GSL (Days)}

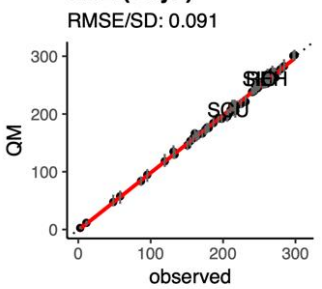

\section{HPE (\# Events)}

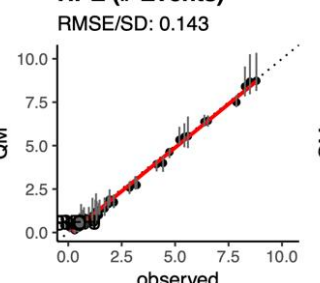

HWC (\# Events)

RMSE/SD: 0.434

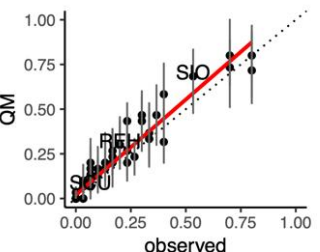

HWL (Days)

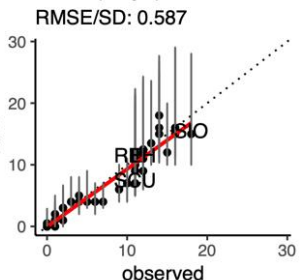

MHWL (Days)

RMSE/SD: 0.226

$$
\text { LFD (Days) }
$$

RMSE/SD: 0.881
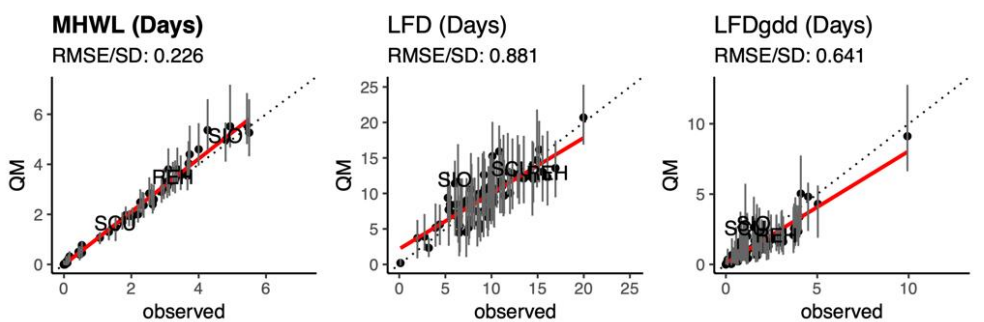

MMT ( $\left.{ }^{\circ} \mathrm{C}\right)$

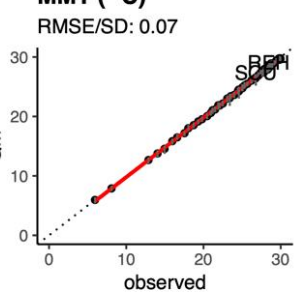

$$
\text { SPEIp (\%) }
$$

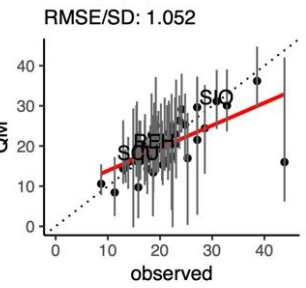

SPEIpVeg (\%)

RMSE/SD: 1.063

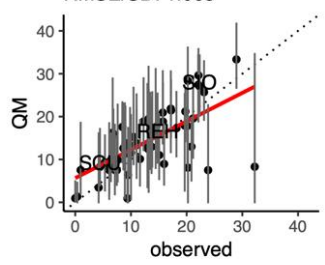

\section{SPEle (\# Events)}

RMSE/SD: 0.773

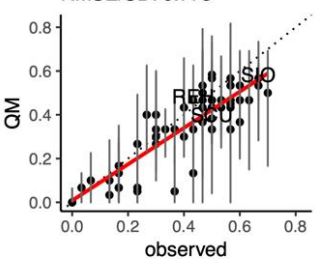

SPEII (Days)

RMSE/SD: 0.813

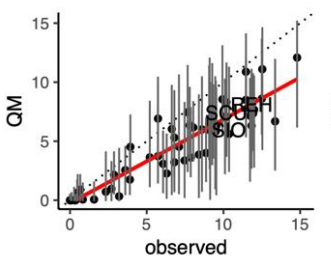

SPIp (\%)

RMSE/SD: 0.872

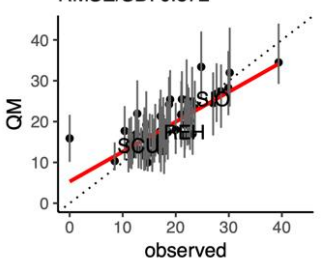

SPIpVeg (\%)

RMSE/SD: 0.949
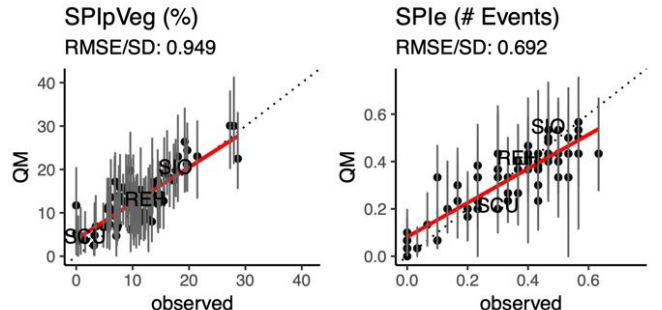

Figure 2. Validation of the 24 indices, shown as scatter plots of observed (x-axis) and quantile mapped (y-axis) values in the historical time period. The standardized RMSE divided by the standard deviation of observed values across stations is used as a performance metric and is indicated in the panel headers. Bold title for class A (RMSE/SD < 0.5) respectively plain for class B indices (RMSE/SD > 0.5). Vertical bars represent the range (5th to 95th quantile) of simulated (quantile-mapped) index values across all individual climate model chains considered per station. Three representative stations for Switzerland's agricultural climate are tagged in each plot: Sion (SIO), Zurich/Reckenholz (REH) and Scuol (SCU). The solid red line represents the linear trend, the grey dashed line indicates the perfect correlation between observed and QM data (1:1 line). 
All degree day related and most of the heat and cold wave indices reveal a good performance with standardized RMSEs mostly below 0.1 and very little model uncertainty for any given station. In case of the degree day indices, a good performance can be expected by definition as the evaluation period 1981-2010 is identical to the QM calibration period and as these indices are based on one climate variable only and involve neither a temporal component nor a component to detect extreme values. The order of these indices for the three representative stations (SIO, REH and SCU) follows the order of its specific climate with a slightly warmer climate in the Valais (SIO) than in Zurich (REH) and a big difference to the colder Alpine setting of Scuol (SCU). Indices that contain an additional temporal component (subgroup of heat and cold waves and GSL) are also represented well with RMSE values below 0.5. In general, however, RMSE values are larger than in the case of simple degree day indices. This feature is to be expected to some extent as the QM method corrects for biases in the simulated quantiles but not for biases in the temporal structure of climate variables. This also leads to a partly considerable climate model uncertainty in the representation of a particular index, as each climate model shows its own (and potentially biased) temporal variability (e.g., CWC, HWC, GSL).

Multivariate indices, i.e., indices that are based on more than one climate variable, and especially those that additionally involve a temporal component are less well represented by the $\mathrm{CH} 2018$ dataset. Standardized RMSE values typically rise above 0.5 . In general, the more variables involved in the calculation of the index the larger the standardized RMSE. SPIpVeg (2 variables involved), for instance, shows a smaller RMSE than SPEIpVeg ( 5 variables involved). A similar behavior is found for SPIp (0.87) and SPIpVeg (0.95) or SPEIp (1.05) and SPEIpVeg (1.06) (Figure 2).

Furthermore, a driver for higher RMSE values is not only an increasing complexity of an index as described by the number of input variables and the consideration of temporal structures, but also the dependency of an index is based on extreme values, i.e., on the tails of the respective distributions. For instance, indices that are based on averaged extremes such as MHWL (average over 30 annual maxima) are showing a smaller RMSE and a better fit between the observed and the QM data than indices that are based on a single extreme value such as the HWL (longest heatwave within a 30-year period). In general, complex indices that show a large standardized RMSE are in many cases also subject to a pronounced model uncertainty at individual stations (see the vertical bars in Figure 2).

Based on the validation routine, the following 12 indices are considered as well-performing and belong to class A (standardized RMSE < 0.5): CWC, DTR, GDD, HDD, CoolingDD, FDD, TDD, GSL, HPE, HWC, MHWL, and MMT. The remaining 12 indices (LFD, LFDgdd, HWL, CDD, CDDVeg, SPIp, SPIpVeg, SPEIp, SPEIpVeg, SPEIe, and SPEIl) are considered as biased and are classified into class B. They show standardized RMSE values larger than 0.5 and are to be treated with special care during the subsequent climate change analysis.

\section{Climate Scenarios}

According to the existing $\mathrm{CH} 2018$ products, the future climate of Switzerland will be characterized by higher temperatures and, among others, reduced summer precipitation (see Chapter 2). We here investigate how these general patterns translate into the individual agricultural indices considered. By doing so we explicitly focus on three distinct patterns of change: (a) horizontal patterns, i.e., the spatial variability of change over the area of Switzerland (Section 5.1); (b) vertical patterns of change, i.e., the dependency of change signals on elevation (Section 5.2); and (c) temporal patterns of change, i.e., the evolution of change signals in the course of the 21st century (Section 5.3).

\subsection{Horizontal Patterns of Change}

The horizontal distributions of the index values in the observed historical period and their respective change signals by the end of the century for RCP2.6 and RCP 8.5 are shown in Figure 3 (class A indices) and Figure 4 (class B indices). All temperature-based indices show a clear tendency towards a warmer climate (increase of GDD, TDD, HWC, MHWL and MMT in Figure 3) and hence less cold weather situations, respectively (decrease of FDD and HDD). This leads to a longer growing 
season (GSL in Figure 3) during which drought periods may occur more often over most parts of the country (increase of CDDVeg, SPIp, SPIpVeg, SPIe, SPEIp, SPEIpVeg, and SPEIe in Figure 4). Additionally, an increase in late frost events (LFD in Figure 4), heavy precipitation events and the diurnal temperature range (HPE and DTR in Figure 3) is found for both emission scenarios.

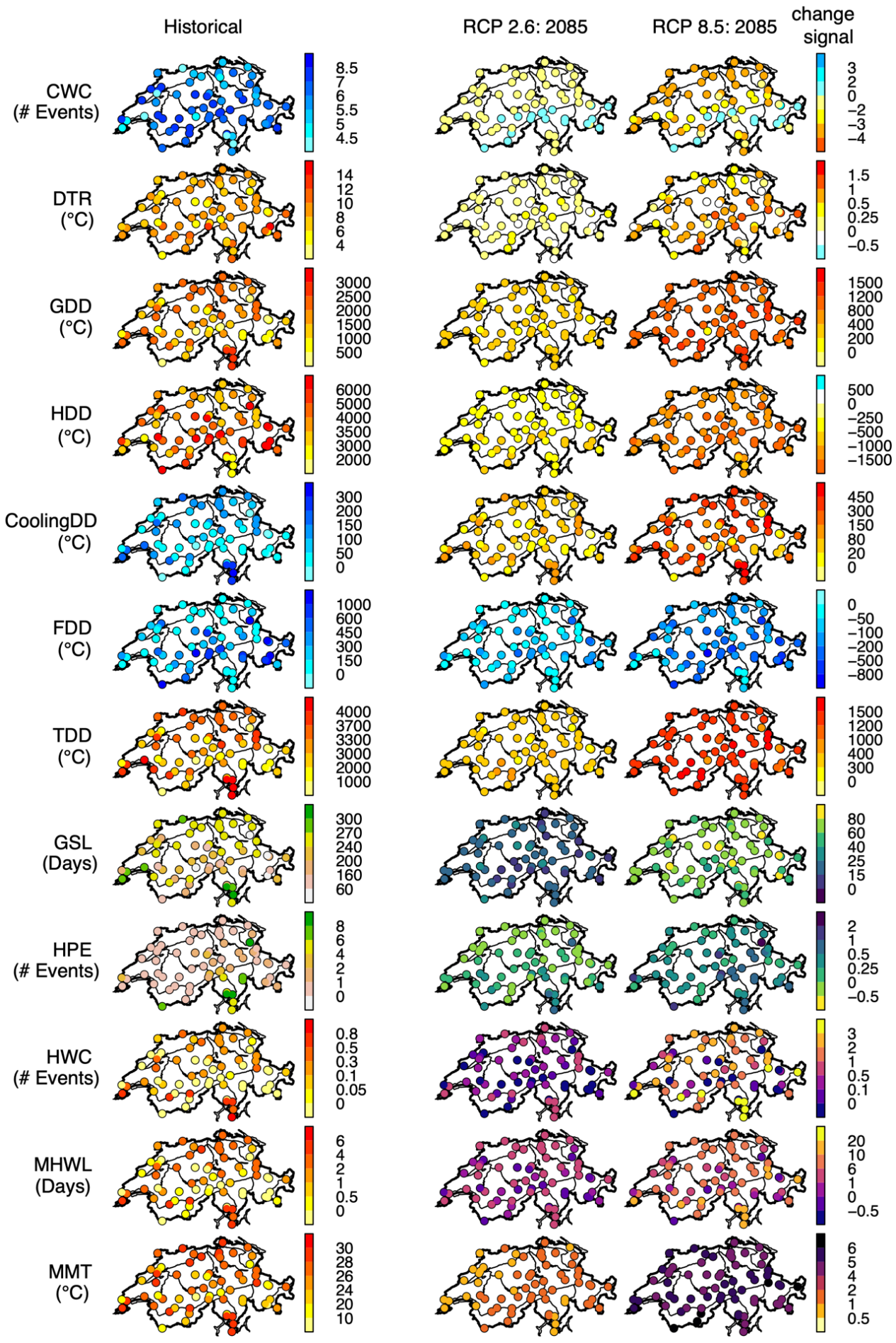

Figure 3. Overview on change signals of class A indices (one index per row). The first column (left column) shows the values of the respective index during the historical period as derived from observations. The second and third columns show the median of the change signal between the historical period and the period 2085 for RCP2.6 (central column) and RCP8.5 (right column). The multi-model median values of the change signal are shown. 


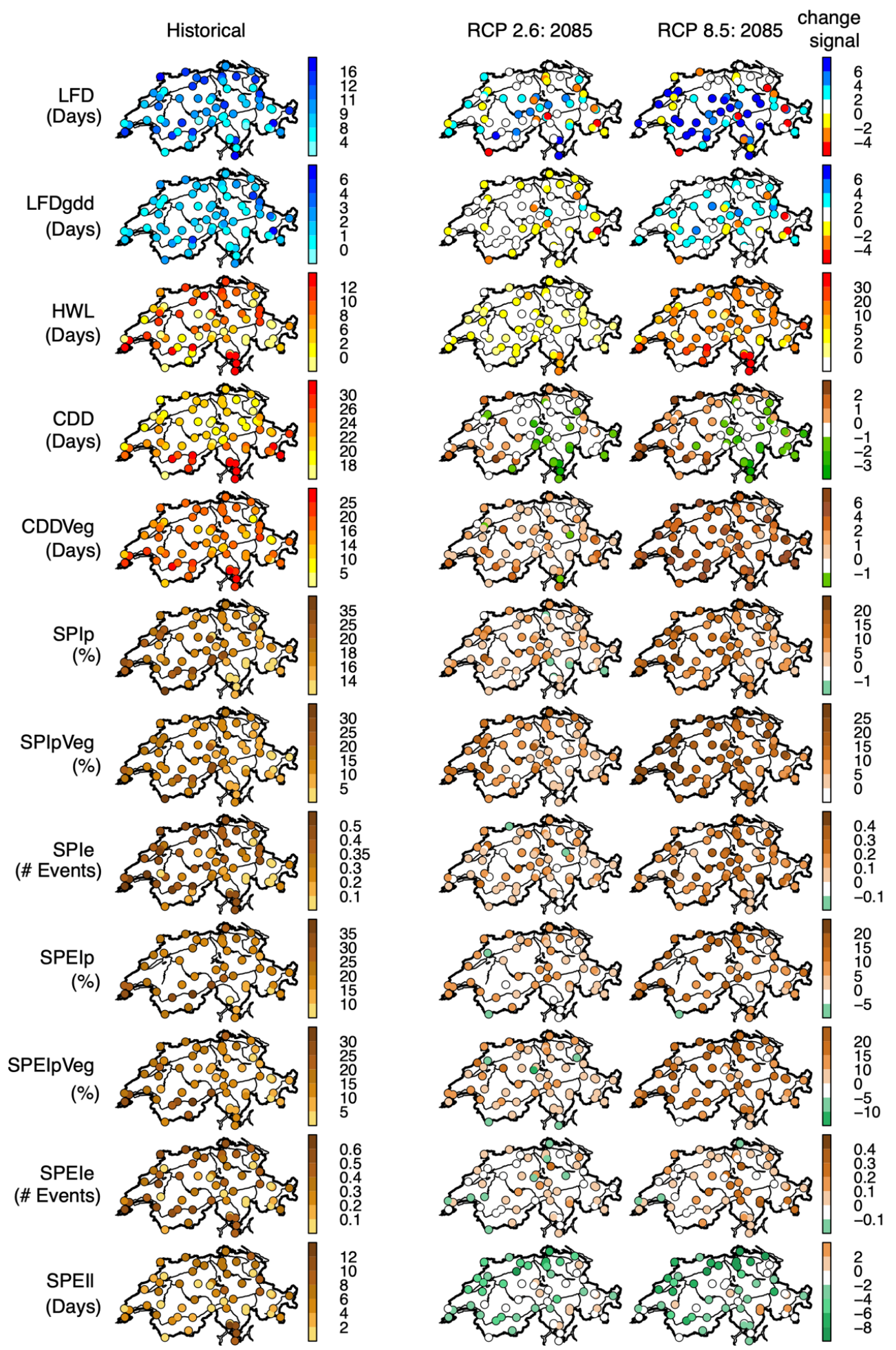

Figure 4. Overview on change signals of class B indices (one index per row). The first column (left column) shows the values of the respective index during the historical period as derived from observations. The second and third columns show the median of the change signal between the historical period and the period 2085 for RCP2.6 (central column) and RCP8.5 (right column). The multi-model median values of the change signal are shown.

Overall, these qualitative change signals appear over the whole country, whereas the magnitude of change shows a pronounced pattern for some indices. For class A indices, the southern Ticino region reveals a warmer (or less cold, respectively) climate, which is expressed by a more frequent 
surpassing of elevated temperature thresholds (CoolingDD, GDD, HWC, MHWL) and a less frequent undershooting of low temperature thresholds (FDD, HDD). The climatic conditions of the Ticino directly translate into more frequent exceedances of high temperature thresholds. This hence leads to exceptionally strong change signals of high temperature indices. Conversely, low temperature threshold indices exhibit a weak signal, as these low temperatures are hardly reached, even in today's climate. In the Alps, though, with a generally colder climate than the rest of the country, the signals are different: low signals for the exceedance of hot thresholds and large signals for the undershooting of cold thresholds. This is, for instance, apparent at our representative stations for the heat index HWC and for FDD as an example for a cold index. In the reference period and for the station Zurich-Reckenholz (REH), HWC (FDD, respectively) amounts to 0.2 (125.6). For the future period 2085, the respective values are 0.77 (79.87) for RCP2.6 and 2.5 (24.07) for RCP8.5. Conversely, at the Alpine station of Scuol (SCU), the reference period value for HWC (FDD, respectively) is 0.07 (450.46), and in 2085, 0.4 (367.95) for RCP2.6 and 3.3 (170.35) for the RCP 8.5, respectively (Table A1 in Appendix A).

$\mathrm{CWC}$, i.e., the index measuring the number of cold waves, shows a specific horizontal pattern of the change signal: an increase over the Alpine region and a decrease over the rest of the stations. This special behavior can be explained by the definition of this index that counts the number of events with five or more consecutive days of daily minimum temperature below $0{ }^{\circ} \mathrm{C}$. In the Alpine region and in the historical period, these events are often much longer than the minimum length of 5 days. A future temperature increase will be associated with less days undershooting the threshold, but at the same time with a splitting of long-duration events into shorter events and, hence, an increase in the total number of events. In most other parts of the country, cold waves are typically of short duration (less than 5 days). With a warmer climate such conditions become even less frequent and hence the number of cold wave situations decreases.

The remaining class B indices are subject to a comparatively uniform spatial pattern of change, with the exception of the Ticino region in the South of Switzerland. For HWL, the Ticino shows a more positive change signal compared to the rest of the country. Also for CDD, the Ticino and Grisons in the East of the country show a negative change signal, contrary to the western part of the country and also contrary to CDDVeg. This special feature is likely related to the fact that the longest dry periods typically occur outside of the vegetation season in southern Switzerland and the number of dry days in this season is projected to decrease [49,50], hence a decrease of CDD. Change signals for drought-related indices are, again, comparatively uniformly distributed in space with most parts of the country showing a clear tendency towards an increasing frequency of drought conditions, especially during the vegetation period (CDDVeg, SPIpVeg, SPEIpVeg, SPIe and SPEIe). This signal is, however, not represented by the SPEIl index, which shows a negative change signal, indicating shorter periods of extreme drought events.

The two late frost event indicators are showing non-uniform spatial change signals. Some stations, especially in the mountainous regions, are subject to an extreme increase in the number of events, whereas the opposite is true for other stations. In the Alps, the increase may be due to the higher temperature level in the future, which elongates the vegetation period due to an earlier start (LFD) or the growing degree day sum is reached earlier (LFDgdd), respectively, extending the potential period during which late frost events can occur. Also, the decrease in the number of events in other stations may be due to the increasing temperature level which decreases the probability of minimum temperature to fall below $0{ }^{\circ} \mathrm{C}$. Note, however, that change signals of class B indices have to be treated and interpreted with special care as these indices show a poor performance of the QM data in the historical period (see Chapter 4).

In a qualitative sense, the described spatial patterns of change signals of the individual indices apply for both emission scenarios, i.e., for RCP2.6 and RCP8.5 (middle and right column in Figures 3 and 4). However, change signals are in most cases amplified for the RCP8.5 scenario. This result reflects the approximate linear scaling of spatial climate change patterns at regional scale with the change of the global mean temperature (e.g., [51]), a fact that was actually exploited in the frame of 
CH2018 for constructing the multi-model combination (Section 3.1 and [22]). Interestingly, this stability of change patterns for different emission scenarios in many cases also applies for threshold-based indices, as apparent from Figures 3 and 4.

\subsection{Vertical Pattern of Change}

As apparent from the horizontal change patterns described in Section 5.1, the complex topography of Switzerland and especially elevation are obviously important factors determining the spatial variability of the change signals. This is due to the clear relation between temperature and elevation and the fact that many of the agricultural indices considered involve fixed temperature thresholds in their definition. We here provide a dedicated analysis on such elevation effects based on an exemplary subset of temperature-based indices (CWC, GSL, MMT) and based on our representative set of stations, covering elevations from 203 (at Magadino/Cadenazzo) up to 3580 (at Jungfraujoch) meters above sea level.
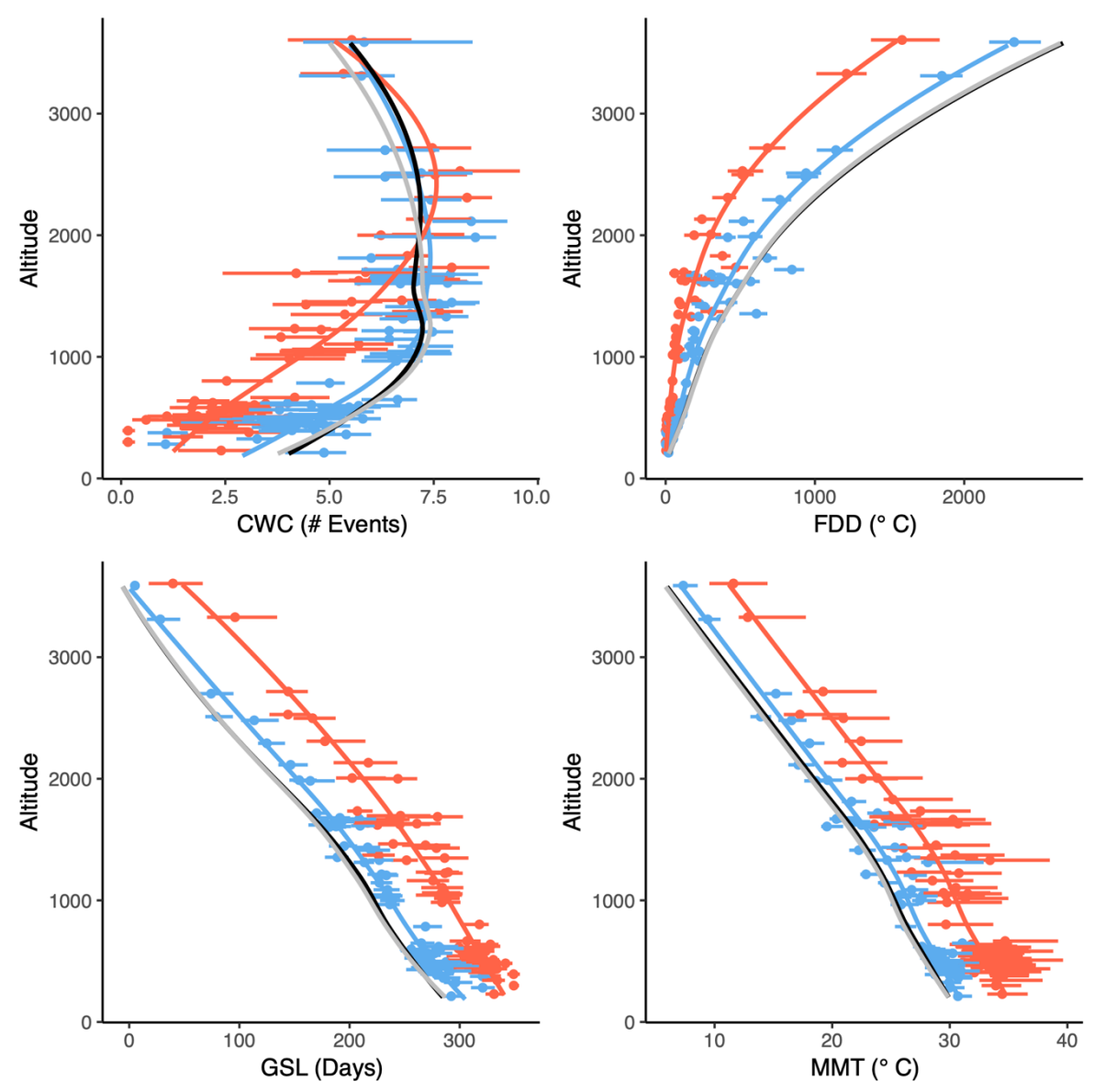

RCP Scenarios 2085

$$
\begin{array}{lll}
\text { - Observation } & \approx \mathrm{RCP} 2.6 \\
\text { - Historical } & \approx \mathrm{RCP} 8.5
\end{array}
$$

Figure 5. Relationship between elevation (y-axis) and the corresponding values of the indices (class A: CWC, FDD, GSL and MMT; $x$-axis). The grey line represents the median of the historical quantile-mapped simulations, the black line denotes the observations (both for the period 1981-2010). All lines were obtained by fitting a local regression trendline through the observations and the simulated median values (indicated by the markers). The blue (red) line represents the RCP2.6 (RCP8.5) scenario with corresponding median values (dots) per station and scenario. Horizontal bars indicate the multi-model range for the future period ( 5 to $95 \%$ confidence interval) at different stations across Switzerland. 
A comparison of elevational profiles of the four investigated indices (Figure 5) indicates a good performance of the quantile-mapped data in the historical period (comparison of grey and black line), confirming the results of Chapter 4 for temperature-based class A indices: Elevational profiles are accurately captured. For GSL and MMT, future climate change will lead to clear increases at all elevations. This is in particular true for RCP8.5. Future values for RCP2.6 are, in general, rather close to their historical counterparts, reflecting the much smaller temperature increase for RCP2.6 $\left(+1.2{ }^{\circ} \mathrm{C}\right.$ increase of annual mean temperature averaged over the area of Switzerland; see [22]) compared to RCP8.5 $\left(+4.3^{\circ} \mathrm{C}\right.$, respectively). Also note that the multi model deviation tends to increase from RCP2.6 to RCP8.5 (width of the horizontal bars). This is consistent with the results of CH2018 [22], which show in general an increased model uncertainty for larger warming signals. For both indices, change signals are similar across the entire elevation range, i.e., the elevation dependency of future climate change is small, except for slightly larger increases of GSL for elevations between about 2000 and 2500. A different pattern becomes apparent for CWC though. While the number of events is projected to decrease below $1800 \mathrm{~m}$, only small changes or even increases are projected at higher reaches, which is related to the specific definition of this index (see Section 5.1). FDD, another cold specific index, also shows an elevational dependency of the change signal with much larger absolute decreases aloft.

\subsection{Temporal Pattern of Change}

Besides horizontal and vertical dependencies, future climate change will likely also be subject to a temporal pattern, i.e., will differ according to the lead time of the projection. Especially for strong emission scenarios, an increasing global mean temperature towards the end of the 21st century can be expected to be associated with amplified changes of climate indices at local scale. Indeed, this is the case for the indices considered in the present work, with change signals increasing over time (change signal $2035<2060<2085$ ). This behavior is illustrated by Figure 6 for the three representative stations and three exemplary indices (GDD, LFDgdd, SPIp). Note that the same style of presentation has already been used for a first set of climate indices in the frame of the existing CH2018 web atlas [52]. Well represented indices of the present work (class A) will in the near future also be available as an addition to the already existing indices and thereby deliver a more complex and complete insight into Switzerland's future climate. One of these class A indices is GDD (first column), which is subject to a steady and close-to-linear increase over time at all three stations. Model uncertainty is found to be relatively small compared to the index values themselves (size of vertical bars), but is increasing with time.

For the class B indices (LFDgdd and SPIp), model uncertainty is much larger, a fact that has already been apparent from the validation routine (Chapter 4) and that underlines the need for a careful interpretation of the change signals. Nevertheless, the temporal pattern of change is similar to the class A index GDD, although LFDgdd is not showing a close-to-linear trend but seems to increase in an exponential-like pattern over time. SPIp, again, is mostly subject to a uniform increase over time. Typically (but not always) model uncertainty increases over time as well. A more detailed overview of index changes over time for all considered indices and for three exemplary stations is provided by Table A1 (class A indices) and Table A2 (class B indices) in Appendix A, respectively. Note the partly deficient reproduction of observed values by the historical bias-corrected data for class B indices (red star compared to grey bar). 

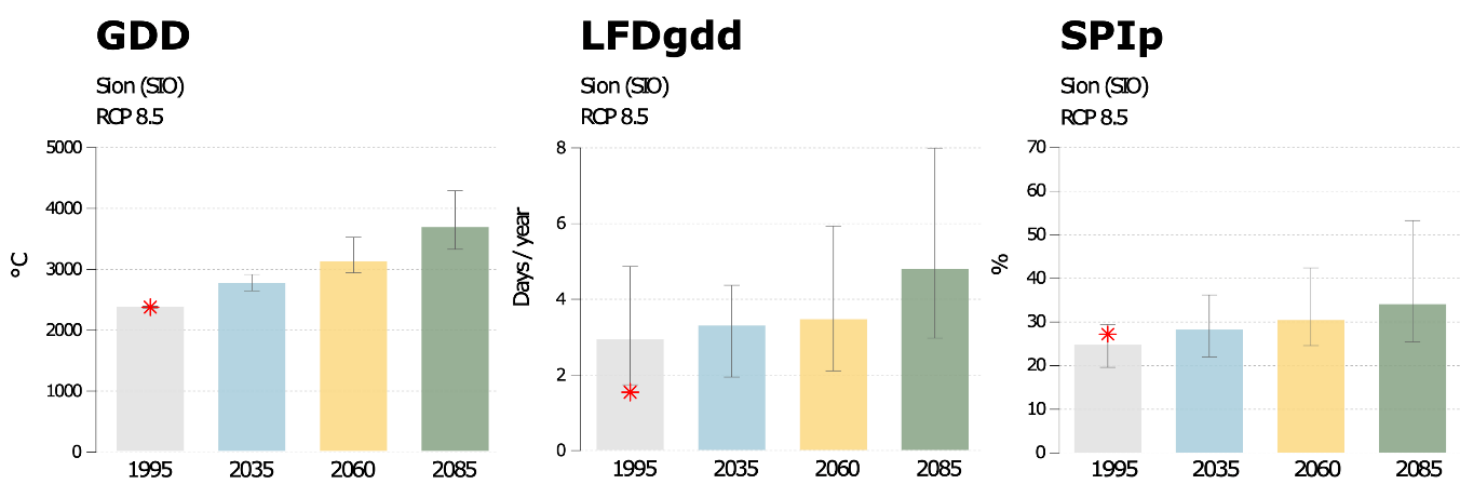

\section{GDD}

Zurich / Affoltern (REH)

RCP 8.5

\section{LFDgdd}

Zurich / Affoltern (REH) RCP 8.5
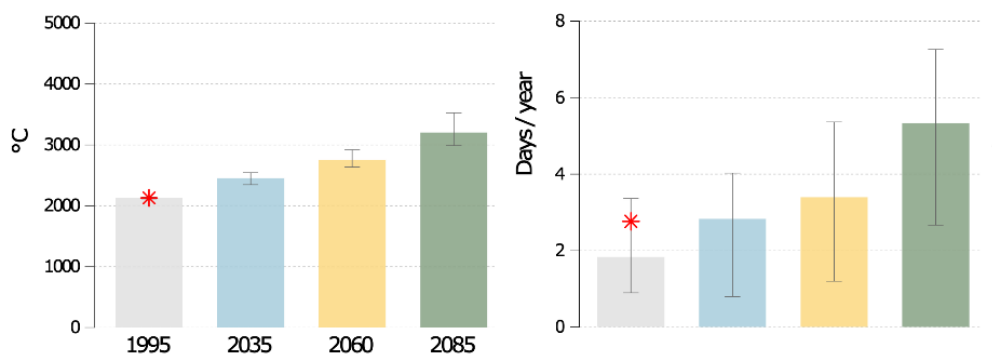

SPIP

Zurich / Affoltern (REH)

RCP 8.5

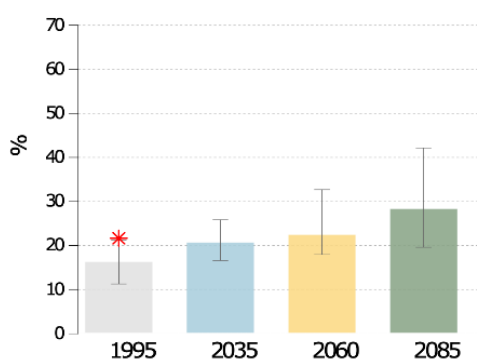

GDD

\section{LFDgdd}

Scuol (sa)

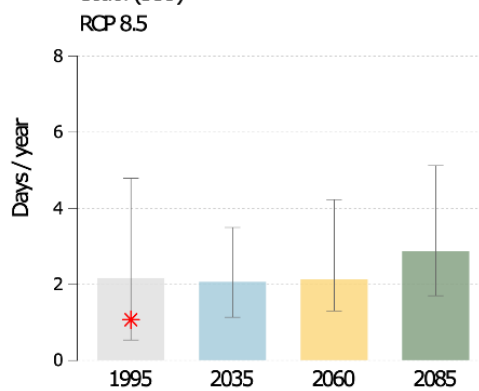

\section{SPIP}

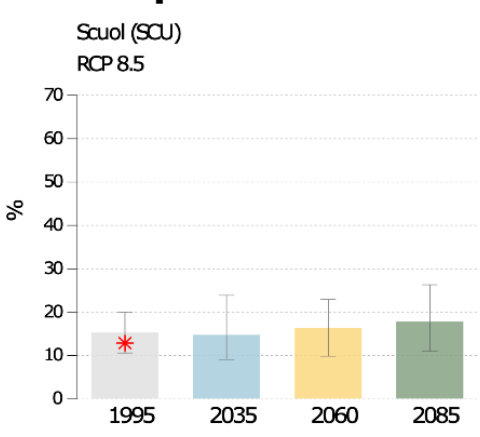

Figure 6. Median values for three selected indices (GDD, LFDgdd and SPIp) for all four periods considered and for the three exemplary stations of Sion (SIO; upper row), Zurich/Affoltern (REH; middle row) and Scuol (SCU; lower row). The red stars refer to the observed value in the reference period. The grey bar (1995) indicates the median values of the quantile-mapped scenario data in the historical reference period. The blue (2035), yellow (2060) and green (2085) bars, respectively, represent future periods assuming the RCP8.5 emission scenario. The whiskers are showing the 5th and 95th quantile.

\section{Discussion and Conclusions}

The present work validates the local CH2018 products with respect to the representation of agricultural climate indices in Switzerland and assesses their projected change signals throughout the 21st century. The validation routine yields good results for indices that are based on one or two climate variables only and that are based on simple temporal aggregations, such as degree-day based temperature indices (class A indices). As expected, indices that are based on multiple climate variables and that involve complex temporal statistics or extreme conditions are less well represented (class $B$ indices). The interpretation of future change signals of these class B indices should be carried out carefully and should explicitly consider the associated projection uncertainties.

Summarizing the results obtained in the climate scenario analysis, the climate of Switzerland is projected to become warmer in the future. Temperature-related extreme events will intensify. 
The growing season will be extended but with that, the risk of droughts during this season is increasing, too. Additionally, the frequency of heat waves is strongly increasing as well as the maximum temperatures these waves will reach. Overall and especially regarding the agricultural sector, Switzerland's climate will become rougher and more challenging.

A clear indication of future climate warming is the degree day indices (CoolingDD, GDD, TDD; Figure 3) and the heat waves (MMT, HWC, MHWL, HWL; Figures 3 and 4), respectively. These indices are projected to increase in the future which will likely lead to challenges for the agricultural sector. High temperatures can lead to yield loss in livestock farming due to heat-stressed animals [53]. However, the rise in temperature will be associated with an elongated growing season (GSL) which can be an advantage for agriculture. Some regions in Switzerland, mostly those located at higher elevations, are today facing a comparatively short vegetation period. Combining the vertical, horizontal and temporal patterns of change, we can see that the growing season (as well as GDD) is increasing with time at higher altitudes all over Switzerland. As some crops favor warm climates (i.e., maize or soybean [54]), the presently short vegetation period can hinder the cultivation of various crops such as cereals or maize, because they do not mature fast enough. Future climate change might hence be associated with more favorable growing conditions for these cases. However, an extended growing season might also be accompanied by climate-related risks such as an increase in late frost events which can reduce the yield of various crops drastically $[55,56]$. Furthermore, drought events are also likely to occur more often, especially during the vegetation period. Droughts can, as well as late frost events, reduce the yield significantly [57]. The extension of the growing season also means that the cold winter season will become shorter. This is also apparent in the negative change signals of FDD and HDD. For various culture plants, such as winter wheat and horticultural plants, this season is highly relevant for the vernalization process. Vernalization is important to induce the flowering process, which is necessary to gain any yield as the fruits are often the plant part which is harvested [58-60]. If the time span during which cold temperatures are required for this process shortens, the risk that vernalization cannot happen and that no flowering will be induced might increase. This could potentially lead to considerable yield losses.

Understanding future climate change and its challenges is crucial to find solutions to maintain a functioning agriculture delivering steady yield. However, climate scenario products such as those provided by $\mathrm{CH} 2018$ should not be used without a proper assessment of their suitability to answer specific questions regarding future climate change at local scales. In the present work, we found that it is extremely important to validate the representation of the specific climate indices under consideration. This is especially true for more complex research questions where a combination of multiple climate variables involving a certain temporal pattern is applied. In this study, complex indices (drought related indices, or late frost events) were poorly represented compared to others (degree day-based indices, for instance). Obviously, the awareness of potential data limitations is important to avoid a misinterpretation of the results obtained. In agricultural climate impact studies, complex models employing several environmental variables are frequently applied. In such cases, not just the agricultural model itself should be carefully validated, but also the respective climatological input data. Still, the assessment of climatic indices including their validation and their future changes only represents a first step in adaptation design. For specific applications, more detailed analyses of the specific conditions and the critical indices for the chosen practice need to be elaborated. Highly individual factors for a given culture of interest and its specific behaviour regarding various environmental impacts and stressors can be expected to play crucial roles.

Climate scenario products such as those provided by CH2018 allow identifying sector-specific potential challenges and opportunities, for instance an increase in the growing season length or the GDD. Knowledge on these issues can help to design future agricultural practices and to support the required transitions of the agricultural system. 
Author Contributions: Conceptualization, F.T., A.M.F. and S.K.; data curation, F.T.; formal analysis, F.T.; funding acquisition, S.K.; methodology, F.T., I.F., A.M.F. and S.K.; project administration, S.K.; software, I.F.; supervision, A.M.F. and S.K.; validation, F.T. and S.K.; visualization, F.T., I.F., A.M.F. and S.K.; writing-original draft, F.T., I.F., A.M.F. and S.K.; writing-review \& editing, F.T. and S.K. All authors have read and agreed to the published version of the manuscript.

Funding: I.F. has received funding from the EU Horizon2020 project SUPER-G under grant agreement N. 774124.

Acknowledgments: The local scenario data were obtained from www.climate-scenarios.ch, doi: 10.18751/Climate/ Scenarios/CH2018/1.0. We thank Jan Rajczak (MeteoSwiss) for his valuable input regarding the interpretation of our results. Part of the visualizations are based on scripts originally written by Moritz Pickl (Karlsruhe Institute of Technology).

Conflicts of Interest: The authors declare no conflict of interest.

\section{Appendix A}

Table A1. Median values for class A indices as represented by observations (reference) and by the quantile-mapped CH2018 data for all time periods (historical, 2035, 2060 and 2085) and the two emission scenarios (RCP2.6 and RCP8.5) for the three representative stations SIO, REH and SCU.

\begin{tabular}{|c|c|c|c|c|c|c|c|c|c|c|c|c|c|c|}
\hline Station & Period & Scenario & CWC & DTR & GDD & HDD & $\begin{array}{l}\text { Cooling } \\
\text { DD }\end{array}$ & FDD & TDD & GSL & HPE & HWC & MHWL & MMT \\
\hline \multirow[t]{8}{*}{ SIO } & reference & & 6.43 & 11.2 & 2361.29 & 3189.37 & 170.59 & 110.57 & 3811.92 & 250.7 & 0.07 & 0.53 & 4.8 & 29.85 \\
\hline & historical & & 6.5 & 11.15 & 2365.06 & 3207.87 & 170.36 & 114.48 & 3805.44 & 255.17 & 0.27 & 0.67 & 4.93 & 29.46 \\
\hline & 2035 & RCP2.6 & 5.77 & 11.32 & 2649.31 & 2938.01 & 261.66 & 80.36 & 4150.49 & 263.17 & 0.33 & 1.4 & 8.03 & 31.06 \\
\hline & & RCP8.5 & 5.53 & 11.38 & 2755.15 & 2795.71 & 296.01 & 70.59 & 4267.6 & 270.63 & 0.37 & 1.73 & 8.77 & 31.53 \\
\hline & 2060 & RCP2.6 & 5.7 & 11.35 & 2714.48 & 2853.03 & 276.21 & 72.67 & 4219.06 & 269.9 & 0.37 & 1.53 & 7.67 & 31.22 \\
\hline & & RCP8.5 & 4.93 & 11.58 & 3112.36 & 2499.41 & 446.42 & 49.93 & 4691.12 & 288.43 & 0.43 & 3.1 & 11.83 & 33.15 \\
\hline & 2085 & RCP2.6 & 5.8 & 11.36 & 2690.74 & 2874.67 & 269.13 & 76.73 & 4203.26 & 267.17 & 0.4 & 1.5 & 7.37 & 31.13 \\
\hline & & RCP8.5 & 3.37 & 11.89 & 3674.1 & 2096.45 & 597.62 & 24.81 & 5354.03 & 308.37 & 0.47 & 4.33 & 17.8 & 34.87 \\
\hline \multirow[t]{8}{*}{ REH } & reference & & 5.93 & 9.01 & 2129.62 & 3402.5 & 116.43 & 125.46 & 3571.33 & 260.13 & 0.37 & 0.2 & 3.23 & 28.44 \\
\hline & historical & & 5.77 & 8.99 & 2130.21 & 3410.25 & 117.49 & 126.53 & 3566.77 & 251.63 & 0.37 & 0.3 & 3.37 & 28.19 \\
\hline & 2035 & RCP2.6 & 4.83 & 9.1 & 2366.27 & 3125.96 & 173.03 & 83.32 & 3869.71 & 270.93 & 0.47 & 0.73 & 4.9 & 29.43 \\
\hline & & RCP8.5 & 4.6 & 9.09 & 2451.41 & 3002.33 & 191.15 & 73.03 & 3971.51 & 276.37 & 0.43 & 0.77 & 5.43 & 29.83 \\
\hline & 2060 & RCP2.6 & 4.73 & 9.15 & 2421.14 & 3046.36 & 187.14 & 80.23 & 3928.69 & 274.77 & 0.47 & 0.8 & 5.2 & 29.78 \\
\hline & & RCP8.5 & 3.6 & 9.19 & 2751.27 & 2713.63 & 295.56 & 53.04 & 4335.96 & 295.13 & 0.7 & 1.47 & 8 & 31.19 \\
\hline & 2085 & RCP2.6 & 4.8 & 9.15 & 2391.81 & 3044.86 & 182.41 & 79.87 & 3897.38 & 273.2 & 0.43 & 0.77 & 5.17 & 29.54 \\
\hline & & RCP8.5 & 2.57 & 9.48 & 3203.21 & 2297.36 & 453.21 & 24.07 & 4859.71 & 319.97 & 0.8 & 2.5 & 11.23 & 33.22 \\
\hline \multirow[t]{8}{*}{ SCU } & reference & & 5.43 & 11.25 & 1327.89 & 4846.2 & 14.82 & 450.46 & 2472.17 & 207.13 & 0.57 & 0.07 & 1.53 & 26.78 \\
\hline & historical & & 6.23 & 11.23 & 1335.06 & 4853.87 & 14.17 & 460.18 & 2478.02 & 200.53 & 0.33 & 0.1 & 1.53 & 26.53 \\
\hline & 2035 & RCP2.6 & 6.57 & 11.56 & 1603.5 & 4395.57 & 42.82 & 372.68 & 2814.41 & 211.93 & 0.4 & 0.37 & 3.37 & 28.12 \\
\hline & & RCP8.5 & 6.8 & 11.63 & 1688.86 & 4298.18 & 56.68 & 347.46 & 2917 & 213.07 & 0.5 & 0.5 & 4.17 & 28.86 \\
\hline & 2060 & $\mathrm{RCP} 2.6$ & 6.63 & 11.65 & 1643.96 & 4323.45 & 48.34 & 360.17 & 2873.05 & 214.4 & 0.43 & 0.43 & 3.83 & 28.59 \\
\hline & & RCP8.5 & 6.67 & 12.17 & 1993.16 & 3881.61 & 129.53 & 271.49 & 3285.75 & 231.93 & 0.53 & 1.4 & 7 & 30.58 \\
\hline & 2085 & RCP2.6 & 6.77 & 11.65 & 1626.7 & 4389.44 & 48.11 & 367.95 & 2836.91 & 213.5 & 0.5 & 0.4 & 3.8 & 28.14 \\
\hline & & RCP8.5 & 6.83 & 12.69 & 2532.14 & 3315.58 & 297.95 & 170.35 & 3931.64 & 251.77 & 0.7 & 3.3 & 13.47 & 33.42 \\
\hline
\end{tabular}

Table A2. Median values for class B indices as represented by observations (reference) and by the quantile-mapped CH2018 data for all time periods (historical, 2035, 2060 and 2085) and the two emission scenarios (RCP2.6 and RCP8.5) for the three representative stations SIO, REH and SCU.

\begin{tabular}{|c|c|c|c|c|c|c|c|c|c|c|c|c|c|c|}
\hline Station & Period & Scenario & LFD & $\begin{array}{l}\text { LFD } \\
\text { gdd }\end{array}$ & HWL & CDD & $\begin{array}{c}\text { CDD } \\
\text { Veg }\end{array}$ & SPIp & $\begin{array}{c}\text { SPIp } \\
\text { Veg }\end{array}$ & SPIe & SPEIp & $\begin{array}{l}\text { SPEIp } \\
\text { Veg }\end{array}$ & SPEIe & SPEIl \\
\hline \multirow[t]{8}{*}{$\mathrm{SIO}$} & reference & & 6.03 & 1.53 & 18 & 28.4 & 23.7 & 27.04 & 17.64 & 0.47 & 30.86 & 22.34 & 0.67 & 10.37 \\
\hline & historical & & 12.07 & 2.93 & 15 & 30.53 & 25.57 & 24.01 & 18.87 & 0.53 & 30.16 & 24.62 & 0.57 & 5.78 \\
\hline & 2035 & RCP2.6 & 12.43 & 3.57 & 19 & 31.23 & 27.73 & 25.7 & 21.6 & 0.53 & 36.24 & 31.79 & 0.62 & 6.05 \\
\hline & & RCP8.5 & 12.57 & 3.3 & 21 & 30.1 & 26.8 & 28.07 & 26.71 & 0.53 & 36.89 & 33.19 & 0.52 & 5.12 \\
\hline & 2060 & RCP2.6 & 11.97 & 3.33 & 20 & 31.67 & 27.6 & 26.1 & 24.46 & 0.57 & 37.44 & 32.32 & 0.57 & 4.77 \\
\hline & & RCP8.5 & 12.8 & 3.47 & 32 & 29.93 & 28 & 30.26 & 28.94 & 0.6 & 39.05 & 35.89 & 0.63 & 4.65 \\
\hline & 2085 & $\mathrm{RCP} 2.6$ & 12.6 & 3.2 & 20 & 31.67 & 27.03 & 27.12 & 25.67 & 0.57 & 37.39 & 32.26 & 0.62 & 4.82 \\
\hline & & $\mathrm{RCP} 8.5$ & 13.07 & 4.8 & 46 & 31.1 & 29.53 & 33.89 & 32.89 & 0.63 & 45.23 & 42.26 & 0.6 & 2.63 \\
\hline \multirow[t]{8}{*}{ REH } & reference & & 16.07 & 2.77 & 11 & 22.23 & 18.83 & 21.65 & 12.33 & 0.37 & 18.89 & 14.78 & 0.43 & 11.83 \\
\hline & historical & & 11.93 & 1.77 & 11 & 21.03 & 18 & 16.46 & 11.05 & 0.37 & 19.82 & 14.89 & 0.47 & 7.7 \\
\hline & 2035 & RCP2.6 & 14.27 & 3 & 14 & 20.73 & 18.47 & 19.06 & 16.57 & 0.5 & 24.21 & 21.22 & 0.5 & 5.3 \\
\hline & & RCP8.5 & 14.17 & 2.83 & 14 & 20.7 & 17.47 & 20.69 & 20.11 & 0.43 & 27.25 & 23.25 & 0.48 & 4.38 \\
\hline & 2060 & RCP2.6 & 15.67 & 2.67 & 17 & 21.13 & 18.3 & 20.61 & 17.89 & 0.5 & 25.93 & 23.5 & 0.53 & 4.8 \\
\hline & & $\mathrm{RCP} 8.5$ & 16.4 & 3.4 & 20 & 20.7 & 19.27 & 22.43 & 20.16 & 0.5 & 28.88 & 25.73 & 0.58 & 4.43 \\
\hline & 2085 & RCP2.6 & 13.93 & 2.93 & 15 & 21.17 & 17.9 & 20.85 & 18.92 & 0.5 & 24.66 & 22.16 & 0.48 & 5.2 \\
\hline & & RCP8.5 & 14.1 & 5.33 & 28 & 21.17 & 20.17 & 28.36 & 25.02 & 0.7 & 34.13 & 36.22 & 0.62 & 3.12 \\
\hline \multirow[t]{8}{*}{$\mathrm{SCU}$} & reference & & 12.27 & 1.07 & 11 & 29.73 & 19.33 & 12.99 & 1.57 & 0.3 & 15.87 & 4.43 & 0.5 & 10.2 \\
\hline & historical & & 12.8 & 2.13 & 7 & 29.67 & 18.73 & 14.63 & 3.66 & 0.23 & 18.13 & 7.81 & 0.4 & 7.13 \\
\hline & 2035 & RCP2.6 & 13.3 & 2.17 & 12 & 29 & 19.47 & 16.85 & 6.72 & 0.33 & 20.58 & 11.82 & 0.47 & 6.4 \\
\hline & & RCP8.5 & 12.1 & 2.07 & 13 & 27.77 & 18.93 & 14.92 & 7.83 & 0.33 & 19.66 & 10.59 & 0.45 & 7.5 \\
\hline & 2060 & $\mathrm{RCP} 2.6$ & 12.57 & 2.2 & 13 & 28.5 & 19.77 & 16.06 & 7.71 & 0.4 & 20.45 & 11.49 & 0.47 & 7.5 \\
\hline & & RCP8.5 & 12.8 & 2.13 & 17 & 26.77 & 20.6 & 16.48 & 7.45 & 0.33 & 22.73 & 11.93 & 0.47 & 7.2 \\
\hline & 2085 & RCP2.6 & 13.2 & 2.07 & 12 & 28.6 & 19.5 & 17.47 & 8.27 & 0.33 & 19.92 & 10.95 & 0.47 & 6.7 \\
\hline & & RCP8.5 & 14.9 & 2.87 & 36 & 26.87 & 21.93 & 18.03 & 9.69 & 0.47 & 25.96 & 16.05 & 0.57 & 8 \\
\hline
\end{tabular}




\section{References}

1. World Meteorological Organization. WMO Statement on the Status of the Global Climate in 2013; WMO-No. 1233; WMO: Geneva, Switzerland, 2019; ISBN 978-92-63-11233-0.

2. IPCC. Summary for Policymakers. In Climate Change 2013: The Physical Science Basis. Contribution of Working Group I to the Fifth Assessment Report of the Intergovernmental Panel on Climate Change; Stocker, T.F., Qin, D., Plattner, G.-K., Tignor, M., Allen, S.K., Boschung, J., Nauels, A., Xia, Y., Bex, V., Midgley, P.M., Eds.; Cambridge University Press: Cambridge, UK; New York, NY, USA, 2013.

3. Bindoff, N.L.; Stott, P.A.; AchutaRao, K.M.; Allen, M.R.; Gillett, N.; Gutzler, D.; Hansingo, K.; Hegerl, G.; $\mathrm{Hu}$, Y.; Jain, S.; et al. Detection and Attribution of Climate Change: From Global to Regional. In Climate Change 2013: The Physical Science Basis. Contribution of Working Group I to the Fifth Assessment Report of the Intergovernmental Panel on Climate Change; Stocker, T.F., Qin, D., Plattner, G.-K., Tignor, M., Allen, S.K., Boschung, J., Nauels, A., Xia, Y., Bex, V., Midgley, P.M., Eds.; Cambridge University Press: Cambridge, UK; New York, NY, USA, 2013.

4. Collins, M.; Knutti, R.; Arblaster, J.; Dufresne, J.-L.; Fichefet, T.; Friedlingstein, P.; Gao, X.; Gutowski, W.J.; Johns, T.; Krinner, G.; et al. Long-Term Climate Change: Projections, Commitments and Irreversibility. In Climate Change 2013: The Physical Science Basis. Contribution of Working Group I to the Fifth Assessment Report of the Intergovernmental Panel on Climate Change; Stocker, T.F., Qin, D., Plattner, G.-K., Tignor, M., Allen, S.K., Boschung, J., Nauels, A., Xia, Y., Bex, V., Midgley, P.M., Eds.; Cambridge University Press: Cambridge, UK; New York, NY, USA, 2013.

5. Hewitson, B.; Janetos, A.C.; Carter, T.R.; Giorgi, F.; Jones, R.G.; Kwon, W.-T.; Mearns, L.O.; Schipper, E.L.F.; Aalst, M. Regional context. In Climate Change 2014: Impacts, Adaptation, and Vulnerability. Part B: Regional Aspects. Contribution of Working Group II to the Fifth Assessment Report of the Intergovernmental Panel on Climate Change; Barros, V.R., Field, C.B., Dokken, D.J., Mastrandrea, M.D., Mach, T., Bilir, E., Chatterjee, M., Ebi, K.L., Estrada, Y.O., Genova, R.C., et al., Eds.; Cambridge University Press: Cambridge, UK; New York, NY, USA, 2014.

6. Intergovernmental Panel on Climate Change. Summary for Policymakers. In Climate Change and Land: An IPCC Special Report on Climate Change, Desertification, Land Degradation, Sustainable Land Management, Food Security, and Greenhouse Gas Fluxes in Terrestrial Ecosystems; Shukla, P.R., Skea, J., Buendia, E.C., Masson-Delmotte, V., Pörtner, H.-O., Roberts, D.C., Zhai, P., Slade, R., Connors, S., Diemen, R., et al., Eds.; IPCC: Geneva, Switzerland, 2019.

7. Nelson, G.; Rosegrant, M.; Koo, J.; Robertson, R.; Sulser, T.; Zhu, T.; Ringler, C.; Msangi, S.; Palazzo, A.; Batka, M.; et al. Climate Change: Impact on Agriculture and Costs of Adaptation; International Food Policy Research Institute: Washington, DC, USA, 2009; ISBN 978-0-89629-535-3.

8. Smit, B.; Skinner, M.W. Adaptation options in agriculture to climate change: A typology. Mitig. Adapt. Strateg. Glob. Change 2002, 7, 85-114. [CrossRef]

9. Falloon, P.; Betts, R. Climate impacts on European agriculture and water management in the context of adaptation and mitigation-The importance of an integrated approach. Sci. Total Environ. 2010, 408, 5667-5687. [CrossRef] [PubMed]

10. Fan, X.; Fei, C.J.; McCarl, B.A. Adaptation: An agricultural challenge. Climate 2017, 5, 56. [CrossRef]

11. Bestelmeyer, B.T.; Okin, G.S.; Duniway, M.C.; Archer, S.R.; Sayre, N.F.; Williamson, J.C.; Herrick, J.E. Desertification, land use, and the transformation of global drylands. Front. Ecol. Environ. 2015, 13, $28-36$. [CrossRef]

12. Giorgi, F. Thirty Years of Regional Climate Modeling: Where Are We and Where Are We Going next? J. Geophys. Res. Atmos. 2019, 124, 5696-5723. [CrossRef]

13. Maraun, D.; Brienen, S.; Rust, H.W.; Sauter, T.; Themeßl, M.; Venema, V.K.C.; Chun, K.P. Precipitation Downscaling under Climate Change: Recent Developments to Bridge the Gap between Dynamical Models and the End User. Rev. Geophys. 2010, 1-34. [CrossRef]

14. Coordinated Regional Downscaling Experiment. Available online: www.cordex.org (accessed on 20 May 2020).

15. Giorgi, F.; Jones, C.; Arsar, G.R. Addressing climate information needs at the regional level: The CORDEX framework. WMO Bull. 2009, 58, 175-183.

16. Jacob, D.; Petersen, J.; Eggert, B.; Alias, A.; Christensen, O.B.; Bouwer, L.M.; Braun, A.; Colette, A.; Déqué, M.; Georgievski, G.; et al. EURO-CORDEX: New high-resolution climate change projections for European impact research. Reg. Environ. Change 2014, 14, 563-578. [CrossRef] 
17. Kotlarski, S.; Keuler, K.; Christensen, O.B.; Colette, A.; Déqué, M.; Gobiet, A.; Goergen, K.; Jacob, D.; Lüthi, D.; Van Meijgaard, E.; et al. Regional climate modeling on European scales: A joint standard evaluation of the EURO-CORDEX RCM ensemble. Geosci. Model Dev. 2014, 7, 1297-1333. [CrossRef]

18. Feigenwinter, I.; Kotlarski, S.; Casanueva, A.; Fischer, A.; Schwierz, C.; Liniger, M.A. Exploring Quantile Mapping as a Tool to Produce User Tailored Climate Scenarios for Switzerland; Technical Report MeteoSwiss No. 270; MeteoSwiss: Zürich, Switzerland, 2018.

19. Kotlarski, S.; Rajczak, J. Documentation of the Localized CH2018 Datasets. Transient Daily Time Series at the Local Scale: DAILY-LOCAL, DAILY-GRIDDED. Version 1.2. Available online: https://www.nccs.admin.ch/ nccs/de/home/materialien-und-daten/daten/ch2018---klimaszenarien-fuer-die-schweiz.html (accessed on 20 May 2020).

20. Maraun, D.; Shepherd, T.; Widmann, M.; Zappa, G.; Walton, D.; Gutiérrez, J.; Hagemann, S.; Richter, I.; Soares, P.M.M.; Hall, A.; et al. Towards process-informed bias correction of climate change simulations. Nat. Clim. Chang. 2017, 7, 664-773. [CrossRef]

21. Chimani, B.; Heinrich, G.; Hofstätter, M.; Kerschbaumer, M.; Kienberger, S.; Leuprecht, A.; Lexer, A.; Peßenteiner, S.; Poetsch, M.S.; Salzmann, M.; et al. ÖKS15—Klimaszenarien für Österreich. Daten, Methoden und Klimaanalyse. Projektendbericht; Zentralanstalt für Meteorologie und Geodynamik: Wien, Austria, 2016.

22. CH2018 - Climate Scenarios for Switzerland, Technical Report; National Centre for Climate Services: Zurich, Switzerland, 2018; ISBN 978-3-9525031-4-0.

23. Moss, R.H.; Edmonds, J.A.; Hibbard, K.A.; Manning, M.R.; Rose, S.K.; Van Vuuren, D.P.; Carter, T.R.; Emori, S.; Kainuma, M.; Kram, T.; et al. The next generation of scenarios for climate change research and assessment. Nature 2010, 463, 747-756. [CrossRef] [PubMed]

24. National Centre for Climate Services. Climate Scenarios for Switzerland; NCCS: Zurich, Switzerland, 2018; ISBN 978-3-9525031-3-3.

25. Climate Scenarios for Switzerland. Available online: www.climate-scenarios.ch (accessed on 20 May 2020).

26. CH2018 Datasets. Available online: https://www.nccs.admin.ch/nccs/en/home/data-and-media-library/data/ ch2018---climate-scenarios-for-switzerland.html (accessed on 20 May 2020).

27. Soerland, S.; Fischer, A.; Kotlarski, S.; Künsch, H.R.; Ma, L.; Rajczak, J.; Schär, C.; Spirig, C.; Strassmann, K.; Knutti, R. CH2018-National climate scenarios for Switzerland: How to construct consistent multi-model projections from ensembles of opportunity. Submitt. Clim. Serv. 2020. (Under Review).

28. Ivanov, M.A.; Kotlarski, S. Assessing distribution-based climate model bias correction methods over an alpine domain: Added value and limitations. Int. J. Climatol. 2017, 37, 2633-2653. [CrossRef]

29. Jakob Themeßl, M.; Gobiet, A.; Leuprecht, A. Empirical-statistical downscaling and error correction of daily precipitation from regional climate models. Int. J. Climatol. 2011, 31, 1530-1544. [CrossRef]

30. Themeßl, M.J.; Gobiet, A.; Heinrich, G. Empirical-statistical downscaling and error correction of regional climate models and its impact on the climate change signal. Clim. Chang. 2012, 112, 449-468. [CrossRef]

31. Kotlarski, S.; Rajczak, J.; Casanueva, A.; Feigenwinter, I.; Liniger, M. Localized projections. In CH2018-Climate Scenarios for Switzerland, Technical Report; Chapter 5; National Centre for Climate Services: Zurich, Switzerland, 2018; p. 271. ISBN 978-3-9525031-4-0.

32. Frich, P.; Alexander, L.V.; Della-Marta, P.; Gleason, B.; Haylock, M.; Tank Klein, A.M.G.; Peterson, T. Observed coherent changes in climatic extremes during the second half of the twentieth century. Clim. Res. 2002, 19, 193-212. [CrossRef]

33. Zubler, E.M.; Scherrer, S.C.; Croci-Maspoli, M.; Liniger, M.A.; Appenzeller, C. Key climate indices in Switzerland; expected changes in a future climate. Clim. Chang. 2014, 123, 255-271. [CrossRef]

34. American Society of Heating Refrigerating and Air-Conditioning Engineers (Ed.) Energy Estimating and Modeling Methods; SHRAE: Atlanta, GA, USA, 2001.

35. Christenson, M.; Manz, H.; Gyalistras, D. Climate warming impact on degree-days and building energy demand in Switzerland. Energy Convers. Manag. 2006, 47, 671-686. [CrossRef]

36. Lobell, D.B. Changes in diurnal temperature range and national cereal yields. Agric. For. Meteorol. 2007, 145, 229-238. [CrossRef]

37. Karami, M.; Asadi, M. The Phenological Stages of Apple Tree in the North Eastern of Iran. Comput. Water Energy Environ. Eng. 2017, 6, 269-280. [CrossRef]

38. Vitasse, Y.; Rebetez, M. Unprecedented risk of spring frost damage in Switzerland and Germany in 2017. Clim. Chang. 2018, 149, 233-246. [CrossRef] 
39. SIA Standard 381/3: Heating Degree-Days in Switzerland; Swiss Association of Engineers and Architects: Zurich, Switzerland, 1982.

40. Assel, R.A. Maximum freezing degree-days as a winter severity index for the Great Lakes 1897-1977. Mon. Weather Rev. 1980, 108, 1440-1445. [CrossRef]

41. Augspurger, C.K. Spring 2007 warmth and frost: Phenology, damage and refoliation in a temperate deciduous forest. Funct. Ecol. 2009, 23, 1031-1039. [CrossRef]

42. Vitasse, Y.; Schneider, L.; Rixen, C.; Christen, D.; Rebetez, M. Increase in the risk of exposure of forest and fruit trees to spring frosts at higher elevations in Switzerland over the last four decades. Agric. For. Meteorol. 2018, 248, 60-69. [CrossRef]

43. Kistner, E.; Kellner, O.; Andresen, J.; Todey, D.; Morton, L.W. Vulnerability of specialty crops to short-term climatic variability and adaptation strategies in the Midwestern USA. Clim. Chang. 2018, 146, 145-158. [CrossRef]

44. Carisse, O.; Jobin, T.; Bourgeois, G. Predicting apple leaf emergence from degree-day accumulation during the primary scab period. Can. J. Plant Sci. 2008, 88, 229-238. [CrossRef]

45. Vicente-Serrano, S.M.; Beguería, S.; López-Moreno, J.I. A multiscalar drought index sensitive to global warming: The standardized precipitation evapotranspiration index. J. Clim. 2010, 23, 1696-1718. [CrossRef]

46. Hargreaves, G.H. Defining and Using Reference Evapotranspiration. J. Irrig. Drain. Eng. 1994, 120, 1132-1139. [CrossRef]

47. Gudmundsson, L.; Stagge, J.H. Package "SCI": Standardized Climate Indices Such as SPI, SRI or SPEI. 2016. Available online: https://rdrr.io/cran/SCI/man/SCI-package.html (accessed on 20 May 2020).

48. McKee, T.B.; Doesken, N.J.; Kleist, J. The Relationship of Drought Frequency and Duration to Time Scales. In Proceedings of the VIII Conference on Applied Climatology, Anaheim, CA, USA, 17-22 January 1993; pp. 179-184.

49. Rajczak, J.; Schär, C. Projections of Future Precipitation Extremes Over Europe: A Multimodel Assessment of Climate Simulations. J. Geophys. Res. Atmos. 2017, 122, 10773-10800. [CrossRef]

50. Fischer, E.M.; Knutti, R. Anthropogenic contribution to global occurrence of heavy-precipitation and high-temperature extremes. Nat. Clim. Chang. 2015, 5, 560-564. [CrossRef]

51. Herger, N.; Sanderson, B.M.; Knutti, R. Improved pattern scaling approaches for the use in climate impact studies. Geophys. Res. Lett. 2015, 42, 3486-3494. [CrossRef]

52. CH2018 Web Atlas. Available online: https://www.nccs.admin.ch/nccs/en/home/data-and-media-library/ data/ch2018-web-atlas\%20.html (accessed on 20 May 2020).

53. Nardone, A.; Ronchi, B.; Lacetera, N.; Ranieri, M.S.; Bernabucci, U. Effects of climate changes on animal production and sustainability of livestock systems. Livest. Sci. 2010, 130, 57-69. [CrossRef]

54. Jones, C.A.; Ritchie, J.T.; Kiniry, J.R.; Godwin, D.C.; Otter, S.I. The CERES Wheat and Maize Models. In Proceedings of the International Symposium on Minimum Data Sets for Agrotechnoiogy Transfer, Patancheru, India, 21-26 March 1983; pp. 95-100.

55. Zheng, B.; Chapman, S.C.; Christopher, J.T.; Frederiks, T.M.; Chenu, K. Frost trends and their estimated impact on yield in the Australian wheatbelt. J. Exp. Bot. 2015, 66, 3611-3623. [CrossRef] [PubMed]

56. Molitor, D.; Caffarra, A.; Sinigoj, P.; Pertot, I.; Hoffmann, L.; Junk, J. Late frost damage risk for viticulture under future climate conditions: A case study for the Luxembourgish winegrowing region. Aust. J. Grape Wine Res. 2014, 20, 160-168. [CrossRef]

57. Hlavinka, P.; Trnka, M.; Semerádová, D.; Dubrovský, M.; Žalud, Z.; Možný, M. Effect of drought on yield variability of key crops in Czech Republic. Agric. For. Meteorol. 2009, 149, 431-442. [CrossRef]

58. Trione, E.J.; Metzger, R.J. Wheat and Barley Vernalization in a Precise Temperature Gradient. Crop Sci. 1970, 10, 390. [CrossRef]

59. Trevaskis, B.; Hemming, M.N.; Dennis, E.S.; Peacock, W.J. The molecular basis of vernalization-induced flowering in cereals. Trends Plant Sci. 2007, 12, 352-357. [CrossRef]

60. Horvath, D. Common mechanisms regulate flowering and dormancy. Plant Sci. 2009, 177, 523-531. [CrossRef] 